\title{
WestVirginiaUniversity
}

THE RESEARCH REPOSITORY @ WVU

Graduate Theses, Dissertations, and Problem Reports

2017

\section{A Strain Theory of Prosocial Behavior}

\author{
Mallory Slusser
}

Follow this and additional works at: https://researchrepository.wvu.edu/etd

\section{Recommended Citation}

Slusser, Mallory, "A Strain Theory of Prosocial Behavior" (2017). Graduate Theses, Dissertations, and Problem Reports. 6658.

https://researchrepository.wvu.edu/etd/6658

This Thesis is protected by copyright and/or related rights. It has been brought to you by the The Research Repository @ WVU with permission from the rights-holder(s). You are free to use this Thesis in any way that is permitted by the copyright and related rights legislation that applies to your use. For other uses you must obtain permission from the rights-holder(s) directly, unless additional rights are indicated by a Creative Commons license in the record and/ or on the work itself. This Thesis has been accepted for inclusion in WVU Graduate Theses, Dissertations, and Problem Reports collection by an authorized administrator of The Research Repository @ WVU. For more information, please contact researchrepository@mail.wvu.edu. 


\title{
A Strain Theory of Prosocial Behavior
}

\author{
Mallory Slusser \\ Thesis submitted \\ to the Eberly College of Arts and Sciences \\ at West Virginia University \\ in partial fulfillment of the requirements for the degree of \\ Master of Arts in \\ Sociology and Anthropology
}

\author{
Lisa Dilks, Ph.D., Chair \\ Jason Manning, Ph.D. \\ Chris Scheitle, Ph.D \\ Department of Sociology and Anthropology
}

Morgantown, West Virginia

2017

Keywords: General Strain Theory, prosocial behavior, negative emotions, feel bad/do good Copyright 2017 Mallory Slusser 


\title{
ABSTRACT \\ A Strain Theory of Prosocial Behavior
}

\author{
Mallory Slusser
}

Agnew's General Strain Theory proposes that strain leads to negative emotions, which in turn lead to crime and delinquency. However, there has been a lack of research on what happens when the negative emotions that result from externally experienced strains lead to responses other than crime. The psychology literature on "feeling bad, doing good" indicates that internally experienced negative emotions can lead to helping behaviors. The purpose of this research is to examine if externally generated negative emotions can also lead to helping or prosocial behaviors. Particular attention is given to the type of negative emotion that is experienced anger/frustration vs. depression/anxiety - when an individual is exposed to strainful situations. It is proposed that individuals might participate in prosocial behaviors when exposed to strain if they experience depression or anxiety rather than anger or frustration. 


\section{TABLE OF CONTENTS}

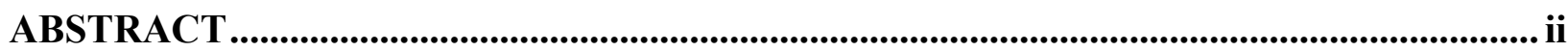

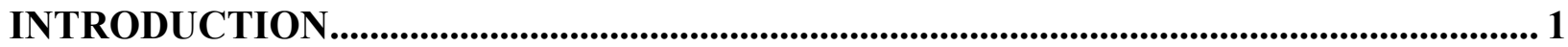

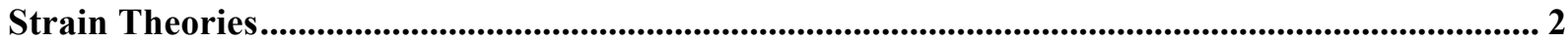

Agnew's General Strain Theory .............................................................................................................. 3

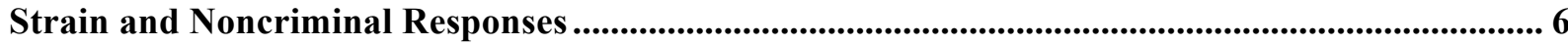

Feel Bad, Do Good .................................................................................................................................. 8

Different Strains, Different Emotions, Different Coping........................................................................ 11

Social Support ............................................................................................................................................ 14

Gender ……......................................................................................................................................... 15

Theoretical Model..................................................................................................................................... 16

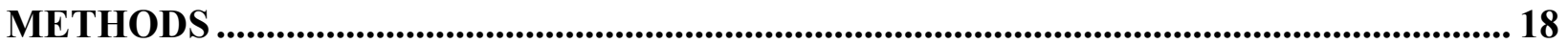

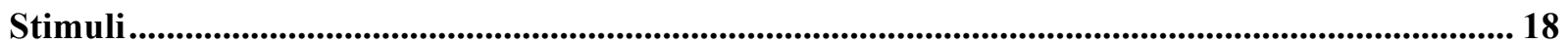

Independent Variables .................................................................................................................................. 19

Dependent Variables .................................................................................................................................... 20

Moderated Path Analyses ............................................................................................................................... 22

Ancillary Analyses: Mediated Path Models ............................................................................................ 32

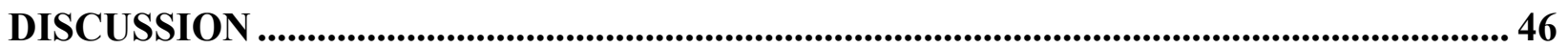

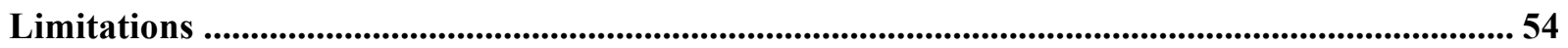

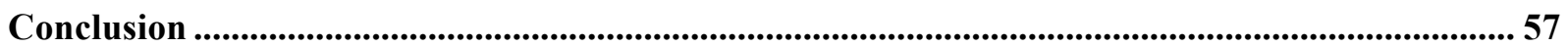

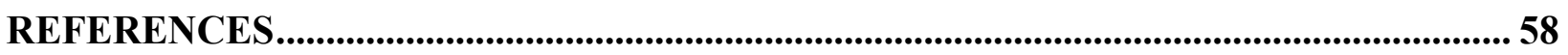

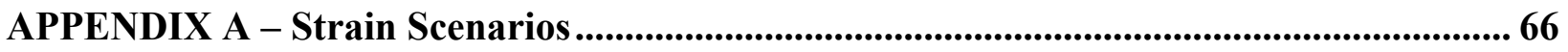

APPENDIX B - Strain Questions.......................................................................................... 68

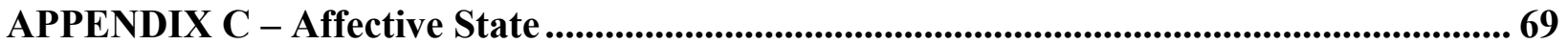

Anger/Frustration...................................................................................................................................... 69

Anxiety/Depression .................................................................................................................................. 69

APPENDIX D - Social Support......................................................................................... 71

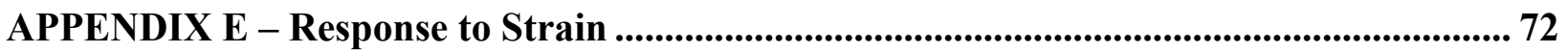

Criminal Responses ...................................................................................................................................... 72

Helping Behavior .............................................................................................................................. 72

APPENDIX F - Frequency of Strain Experience ......................................................................... 74

Interpersonal ............................................................................................................................................ 74

Financial .............................................................................................................................................. 75

Victimization ......................................................................................................................... 77

Academic ……............................................................................................................................... 78

APPENDIX G - Slider Bars.................................................................................................... 81

APPENDIX H - Tables of Direct, Indirect, and Total Effects for Moderating Path Analyses

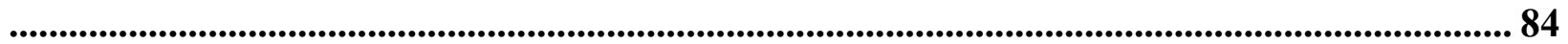

APPENDIX I - Tables of Direct, Indirect, and Total Effects for Mediating Path Analyses 90 


\section{INTRODUCTION}

Negative emotions trigger either constructive or destructive responses in individuals depending on the source of the emotion and the coping resources available. However, the vast majority of literature in strain theory has focused primarily on the relationship between strain and delinquency or crime (Agnew 1992; Agnew 2001; Agnew, Brezina, Wright, and Cullen 2002; Jang and Johnson 2003). Agnew's General Strain Theory (GST) expands the initial strain theory of Merton (1938) by adding the element of emotional responses to strain. According to GST, Agnew (1992) proposes that external sources can cause bad feelings. These negative emotions typically come in the form of anger or frustration, which consequently lead to criminal or delinquent behavior (Agnew 1992; Lee and Cohen 2008).

While there is a plethora of literature that focuses on strain and crime, there is a small portion of the theory, generally overlooked, which asserts that not all strain leads to crime. For instance, the emotional response to strain plays a large part in the type of action taken. Much of the current literature provides support for strain leading to delinquent behavior because individuals were experiencing anger as a result of the strain (Agnew 1992; Broidy 2001; Jang 2007). However, when individuals experience the negative affect of anxiety or depression, they are less likely to respond to strain with criminal or deviant behavior (Broidy 2001; Jang 2007). These findings provide support for the argument that not all strain leads to anger, which in turn leads to aggression. When strain leads to other negative emotions, there is debate regarding how the individual will behave.

There is the potential for individuals to behave prosocially when they experience negative emotions. The literature on "feel bad, do good" states that helping can provide internal rewards, which help to reduce an individual's negative arousal (Myers and Twenge 2013). Individuals are 
motivated "to do good" after they have "done bad" because they are constantly striving to restore and maintain a positive self-image. However, the focus of the previous research in this area has been on bad feelings that arise from internal sources of strain, meaning that the helping behavior had been internally motivated.

At present, the literature has only been pointing in the direction of negative external events leading to individuals participating in undesirable acts (Agnew 1992; Agnew 2001; Agnew, Brezina, Wright, and Cullen 2002; Jang and Johnson 2003). However, there appears to be the potential for those negative external events to cause other emotions that could lead the strained individual in another direction (Broidy 2001; Jang 2007). Taking into consideration the literature on feel bad, do good, it may be possible for these strained individuals to react positively, and even participate in prosocial behaviors. In particular, this research addresses the issue of whether external sources of strain always lead to crime or delinquency, or if certain types of strain can lead to prosocial behaviors. This is done by examining four types of strain, as well as the role that social support plays in shaping different types of negative emotions that lead to either criminal or helping behavior.

\section{Strain Theories}

Most strain theories stemmed from Robert Merton's anomie theory (1938), which examined the influence that roles, class, and cultural factors had on individual deviance. Merton theorized that when individuals failed to achieve culturally specified social goals, including achieving material wealth and status, they would experience strain or anomie. Coping came in the form of legitimate or illegitimate means that were utilized to either accomplish those social objectives, abandon those goals, or resort to any of five different coping strategies: conformity, innovation, ritualism, retreatism, and rebellion (Merton 1938). 
Those who were identified as conformists observed both the socially accepted goals of society (i.e. material wealth) and the institutionally acceptable means of accomplishing them (i.e. working). When individuals do not accept the means of society, but still accept the social goals, they become innovators who engage in deviant behavior as their own means of obtaining them. Conversely, ritualists accept the means of society but have given up on the cultural goals. The retreatists reject both the social goals and institutional means, and resort to withdrawing from society. While rebellion is slightly similar to retreatism in that both individuals reject the means and goals, those coping via rebellion attempt to redefine social norms in the form of countercultures by utilizing violence.

Originally, criminologists used strain theories to understand the relationship between deviance and socioeconomic disadvantage (Cohen 1965). But despite its popularity in early American criminology, anomie theory had its weaknesses. The main tenet of strain theory and its sub-theories was that structural, socioeconomic aspects, such as material deprivation caused individuals to experience strain, which led them to deviant behaviors (Merton 1938). Anomie theory was lacking in that it focused solely on the acquisition of material wealth as a social goal, thus indicating that an inability to achieve that goal was the primary motivation behind deviance and crime. As it stands, this approach is lacking in its ability to explain non-utilitarian, ideological, or malicious crimes that are not driven by a need for material gains. It also fails to explain how strain leads to deviance (Cohen 1997).

\section{Agnew's General Strain Theory}

To address the issues with Merton's (1938) anomie theory, Agnew (1992) restructured strain theory and provided the argument that strain could originate from many sources, above and beyond just the pursuit of material wealth. Strain occurs when an individual feels that others 
are not treating them as they would like to be treated. According to Agnew's GST, strain comes in three forms: 1) the failure to attain positively valued goals, 2) the loss of positively valued stimuli, or 3) the presentation of negatively valued stimuli (Agnew 1992).

Agnew’s (1992) GST and Merton's (1938) anomie theory differ in two key ways. First, there is a difference in the level of sources of strain that cause deviance. Merton (1938) identified macro-level sources of strain, such as culturally and socially defined goals, where Agnew (1992) emphasized micro-level sources of tension that became present in an individual's social learning process or in their immediate social environment. ${ }^{1}$ The second key difference is that anomie theory does not address the role of emotion in crime, whereas Agnew found that emotions are a mediating factor in the relationship between strain and deviant behavior (Agnew 1992; Agnew 2001; Cohen 1965; Cohen 1997).

According to Agnew's theory, strain can come in the form of objective or subjective strains. Objective strains are those that most individuals in a group or society dislike. Conversely, individuals or single members in society dislike subjective strains (Agnew 2001). Agnew (1992) found that strain leads to delinquency when it is chronic or repetitive; is the result of family, peer, or academic stressors; passes a threshold of stressful events; or is very large in magnitude, has occurred recently, is long, and clustered.

As Agnew (2001) developed his General Strain Theory, he was able to better identify the types of strain that were most likely to result in crime or delinquency. In the broad sense of things, strain leads to crime when the strain is viewed as unjust, high in magnitude, the individual lacks social control, and there are perceived benefits from participating in the criminal

\footnotetext{
${ }^{1}$ It is important to note that Agnew (1999) does extend GST to the macro-level. His macro-level strain theory argues that community variation in crime rates is due, in part, to differences in community social conditions. Although not as vigorously tested as general strain theory, several researchers find support for Agnew's macro-level argument (Brezina et al. 2001; Hoffman 2003; Warner and Fowler 2003).
} 
behavior. Therefore, strain will lead to crime if it comes in the form of parental rejection, excessive discipline, child neglect or abuse, working in a secondary labor market, being homeless, having abusive peer relations, or experiencing prejudice and discrimination (Agnew 2001).

However, the relationship between strainful experiences and deviant responses is not wholly direct. Rather, GST argues that strainful experiences give rise to negative emotions, which then lead to deviance and criminal behavior. The idea is that the act has to be the appropriate outlet for relieving the negative emotion experienced with the strain. The goal is ego control through perceived best forms of self-regulation (Roberts, Strayer, and Denham 2014). Specifically, Agnew's (1992: 59) first declaration of his GST paid particular attention to anger, stating that anger is "the most critical emotional reaction for the purposes of the general strain theory." Furthermore, when Lee and Cohen (2008) adapted Agnew's (1992) GST, they paid particular attention to how strain can lead to anger and frustration. Much empirical research confirms the assertion that feelings of anger and frustration led to criminal coping (Broidy 2001; Jang and Johnson 2003; Lee and Cohen 2008). Furthermore, links have been found between negative life stressors, anger, and violent or criminal coping in reference to individual violence (Aseltine, Gore, and Gordon 2000; Jang and Johnson 2003; Piquero and Sealock 2004). Tests of Agnew's theory have indicated large amounts of support for GST (Agnew and Brezina 1997; Agnew and White 1992; Aseltine, Gore, and Gordon 2000; Bao, Haas, and Pi 2004; Baron 2004; Broidy 2001; Jang and Johnson 2003; Lee and Cohen 2008; Moon, Blurton, and McCluskey 2008; Piquero and Sealock 2004). For instance, Broidy (2001) tested Agnew's GST by examining the relationship between strain, negative emotions, coping, and deviant behaviors and found that strain resulting in the negative emotion of anger led to deviant 
behavior. Another test of GST by Agnew and White (1992) examined longitudinal data and indicated a relationship between strain and a disposition to delinquency. Other studies have provided support for Agnew's GST while taking into consideration gender differences in their responses to strain (Jang 2007; Piquero and Sealock 2004; Rebellon, Manasse, Agnew, Van Gundy, and Cohn 2016). However, there appears to be less support for the relationship between strain and noncriminal coping or drug use (Aseltine, Gore, and Gordon 2000; Broidy 2001; Jang and Johnson 2003; Lee and Cohen 2008; Piquero and Sealock 2004).

\section{Strain and Noncriminal Responses}

There is the potential for strain to result in coping that is not criminal or deviant. In fact, some types of strain have been shown to have a weak, or nonexistent relationship with crime. For instance, if the strain is seen as unjust but the individual can rationalize it then they will most likely not resort to criminal coping. When one's socialization and inability to access the legitimate channels of achieving goals cause strain, the individual is more likely to accept it and not act out in anger. Individuals striving to achieve a higher pay or prestige will also accept the strain as a necessary evil of attempting to achieve goals (Agnew 2001).

Even if the strain is related to criminal coping, there is the chance that the individual will find alternatives to the negative behavior. Agnew (1992), Agnew and White (1992), and Lee and Cohen (2008) found that cognitive, emotional, and behavioral adaptations are useful in

preventing criminal responses. Cognitive adaptations come in the form of looking at the stressors from another perspective. Behavioral adaptations work at minimizing or eliminating the cause of the strain, and emotional adaptations are directed towards getting rid of any negative emotions that come with experiencing the strain (Agnew 1992). An individuals' decision to participate in positive or negative coping can be influenced by their own goals, values, or identities, whether or 
not they have coping resources, their level of accessible social support, and if there are constraints to negative behavior. Typical constraints to negative behavior include the weighing of the costs and benefits of participating in the behavior, whether the individual has any form of social control over them, and if they have a lack of access to illegitimate means of achieving their goals (Agnew 1992).

When applied, cognitive adaptations may come in the form of decreasing the importance of the stressor, comparing oneself to similar others, or accepting one's responsibility for the strain that they are experiencing (Agnew 1992). Emotional adaptations can be seen in individuals who turn to drug use to handle their negative emotions, or may exercise or meditate to help reduce the feelings resulting from strain. Of particular interest is the idea of behavioral adaptations, during which individuals focus their energy on trying to achieve other goals of importance or protecting other positively valued stimuli (Agnew 1992).

Noncriminal coping can also occur without the individual utilizing one of the three aforementioned adaptations. For instance, social support, high levels of social control, access to personal resources, and financial resources are useful for preventing an individual from resorting to criminal coping (Agnew 2001; Agnew 2008). If the individual does not have access to those resources, then they could attempt to simply endure the strain. Another solution would be lowering one's need to achieve the goal that they are being prevented from attaining. The strained individual could refocus their energy on trying to pursue another goal that is more realistic and less likely to result in strain (Agnew 2008). On an emotional level, the individual is also less likely to participate in criminal coping if they experience depression and anxiety as a result of the strain (Jang and Johnson 2003). 


\section{Feel Bad, Do Good}

The broadest and most encompassing idea behind GST is that strain makes the individual feel bad, and, based on a desire to reduce those feelings, individuals may engage in deviant behavior believing their deviance will improve their mood (Gollwitzer and Bushman 2011). However, this line of reasoning neglects the fact that other behaviors also reduce feelings of negative emotions and increase mood. The psychology literature has long established that feeling bad can lead to individuals doing good things. For instance, the negative-state relief hypothesis argues that people who are feeling bad will be empathetic to others experiencing negative life events, and will thus be more motivated to help (Batson et al. 1989). According to this hypothesis, individuals are motivated to reduce their own unpleasant feelings by additionally reducing those of others.

Individuals that feel bad may also be motivated to behave prosocially because there is the opportunity to receive positive regard for helping others, which can boost an individual's mood when they feel distressed (Cohen and Wills 1985; Cialdini and Kenrick 1976). Even at a young age, children are socialized to believe that helping others improves mood through praise and thanks (Delamater, Myers, and Collett 2015). The goal in these instances moves from helping because someone needs it, to helping because they think it will make them feel better (Cialdini et al. 1987).

The best indication of an individual's willingness to help when they feel bad can be determined by whether or not they perceive their negative mood to be alterable. Individuals that perceive the benefit of helping (i.e. alleviated negative emotions) to be higher than the costs of helping should be more willing to help, so long as there is hope for mood improvement (Manucia, Baumann, Cialdini 1984). Helping, or prosocial behavior, also has to be the best 
option for altering one's negative mood. If other options, especially less costly ones, are available, then helping will be less likely (Schaller and Cialdini 1988). Sometimes it is characteristics of the request for help that influence an individual's helping behavior. For example, Forest, Clark, Mills, and Isen (1979) discovered that when requests for help were unpleasant ("help, I've broken my leg"), individuals that were experiencing negative feelings were more likely to help.

The most common negative affect studied in this literature is guilt, a feeling that most avoid or attempt to relieve. According to Roberts, Strayer, and Denham (2014), "guilt is an important regulator of self and social development, signaling that a proscription across social and moral domains has occurred or is imminent" (p. 465). Individuals attempt to resolve their guilt through self-blame, taking responsibility for one's actions, and preventing harm to others through self-regulation (Roberts, Strayer, and Denham 2014). There are many cultural differences in relieving guilt, ranging from animal and human sacrifices to confessing one's wrongdoings. Of particular interest is the research that indicates that individuals experiencing guilt may participate in prosocial behaviors, such as an offering of one's harvest or donating money (Myers and Twenge 2013). Roos, Hodges, and Salmivalli (2004) report that in adolescents, guilt is likely to lead to aggression, which in turn leads to prosocial behavior. The purpose of the prosocial behaviors is a sort of moral cleansing that allows ones to improve their self-image (Ding, Xie, Sun, Li, Wang, Zhen 2016).

Some of the literature on feel bad, do good has moved away from the influence of guilt on prosocial behaviors in an attempt to gain an understanding of how other negative emotions motivate individuals to partake in helping. Research by Isen, Horn, and Rosenhan (1973) indicates children wanting to repair their self-image will be more likely to help after 
experiencing failure. Cialdini and Kenrick (1976) found that when individuals were asked to think of depressing events, they were more likely to be privately generous. The only moods that are exceptions to the feel bad, do good phenomena are anger and grief. Anger tends to cause frustration, which in turn leads to aggression, whereas grief causes the individual to turn inward and actually isolate him or herself from others (Myers and Twenge 2013).

These previous findings provide support for the argument that individuals experiencing negative emotions will participate in prosocial behavior. However, all of the literature on "feel bad, do good" is internally or individually generated, such as the individual perceiving that they had done something bad and were the cause of their own misfortunes (Mark and Twenge 2013). But, as evidenced through GST and other strain-based theories, bad feelings can be externally produced as well. Since negative emotion reduction is such a major component of experiencing strain, it is rational to make the argument that strain could lead to helping or criminal behavior, as both have been found to be reactions to experiencing negative emotions (Agnew 1992; Manucia, Baumann, Cialdini 1984; Myers and Twenge 2013).

\section{RESEARCH OBJECTIVES}

This research will attempt to examine how external strains influence an individual's likelihood of participating in prosocial behaviors in response to the negative emotions produced by such strainful experiences. Of the literature examining noncriminal coping to strain, there is nothing that states whether strained individuals would be likely to participate in helping behaviors. Furthermore, while there is a plethora of literature on strain leading to different negative affects, most of the literature focuses on how strain leads to anger (Broidy 2001; Gollwitzer and Bushman 2011; Jang and Johnson 2003; Lee and Cohen 2008; Lowe and May 
2001) thus ignoring other negative emotional reactions to strain, some of which may lead to prosocial behaviors.

\section{Different Strains, Different Emotions, Different Coping}

The first goal of this research is to study various types of strain to see which types of strain elicit different negative emotional affects. A majority of the literature that is focused on strain and emotions has found that different emotions result in different coping behaviors as a result of different strains. The primary finding has been that anger as a result of strain leads to criminal coping, whereas depression leads to noncriminal coping (Jang and Johnson 2003; Sigfusdottir, Farkas, and Silver 2004). An analysis of individual, more subjective interpretations of objective strains revealed the mediating effects of negative emotions on internalized versus externalized coping in the form of drug use and non-drug delinquency. Non-drug delinquency pertained to actions such as physical assault, gang violence, intimidation, robbery, and theft while drug use referred to smoking cigarettes and drinking alcohol. Anger led to an increase in both internal and external coping in the forms of drug use and non-drug delinquency, respectively. They also found that depression and anxiety were not related to drug use and caused a decrease in non-drug delinquency (Jang and Song 2015).

Four major types of strain appear in the literature: interpersonal, academic, financial, and victimization. When examining the strain of family conflict, Sigfusdottir, Farkas, and Silver (2004) found that emotional reactions came equally in the form of both anger and depression. However, anger was found to force the individual into action while it lowered inhibition, explaining why individuals were more likely to participate in delinquent behaviors. On the other hand, individuals experiencing depressed moods were not likely to participate in delinquent behavior (Sigfusdottir, Farkas, and Silver 2004). Bao, Haas, and Pi (2004) found that the 
relationships between interpersonal strain and coping are mediated by a variety of emotions. In particular, they found that anger mediates the effect of strain on violence, while resentment mediates the relationship between strain and nondelinquent behavior. Anxiety and depression also mediated the effects of interpersonal strain on minor offense (Bao, Haas, and Pi 2004). When individuals experience interpersonal strain by perceiving themselves or their loved ones to be physically threatened, they are more likely to respond with anger and aggression (Lowe and May 2011).

Baron (2004) also looked at instances of victimization with homeless street youth in the form of emotional, physical, or sexual abuse, robbery or theft, relative deprivation, violent victimization, and monetary dissatisfaction. All, except for robbery or theft, were found to lead to anger, with violent victimization and emotional abuse being the most significant predictors of anger. Bullying and criminal victimization also have a positive relationship with both anger and criminal coping (Moon, Blurton, and McCluskey 2008). In terms of the temporal occurrence of stressors, criminal victimization is the only stressor to maintain a statistically significant relationship with anger and deviant coping regardless of whether the victimization occurred recently or was older. Meanwhile bullying had a statistically significant relationship with anger and deviant behavior when the bullying was chronic (Moon, Blurton, and McCluskey 2008).

Studies of strain in the education context indicate that school can be an external source of strain for students, which in turn leads to delinquent behaviors in the school environment (Lee and Cohen 2008). Academic strain can occur regardless of one's levels of academic aspirations, as well as their perceived expectations and outcomes (Tedor, Sharp, and Kobayashi 2015). Exposure to learning opportunities does appear to curb criminal coping because they can learn new things and apply those new things, rather than utilize negative coping strategies (Staff and 
Ugen 2003). Mathew, Khakha, Qureshi, Sagar, and Khaka (2015) explain that stressors, such as failure or low grades, are actually more distressful than stressors that are more uncontrollable, for instance family events or accidents or even controllable events, such as sexual relationships. Their argument is that distressful events cause significantly less stress than uncontrollable, or even controllable stressors, thus resulting in less need to either internalize or externalize the emotions experienced from the stressful event (Mathew et al. 2015). Should academic strains lead to criminal coping, it is because the stressors increase depressive levels, lower school engagement, and create more opportunities for connections with delinquent individuals (Lin and Yi 2016).

People of any age experience financial strain, even youth. Moon, Blurton, and McCluskey (2008) found that youth experiencing financial strain were more likely to participate in delinquent behaviors, however the relationship was only statistically significant if the stressor was older, and not more recent. Baron (2007) looked once again at homeless street youths and examined them from the financial strain perspective by taking into consideration their status of homelessness, monetary dissatisfaction and relative deprivation to examine the relationship those stressors had with violent and property crime. Monetary dissatisfaction led to incidences of property crimes by both males and females, whereas homelessness led to violent offending in females and relative deprivation led to violent offending in males. Anger appeared to be a significant predictor of criminal coping for both males and females in the case of these homeless youth. Females were more likely to experience anger, which may have been due to a perceived lack of self-efficacy (Baron 2007). 


\section{Social Support}

The second goal of this research is to determine how social support influences different types of negative emotions that lead to either criminal coping or helping behaviors. Social support is given special attention in this study because research indicates that an individual's perceived level of social support influences their reaction to external stressors and strain (Agnew 1992; Cohen and Wills 1985). Social support is effective when the interpersonal relations meet the needs of the strained individual. Individuals that are especially integrated in society are more likely to experience social support than those who are not as socially integrated. These people may also be more likely to cope non-criminally simply because increased well-being is associated with integration (Cohen and Wills 1985).

When people feel sad, it appears as though social support is the best coping strategy, whereas anger and shame are best handled through problem solving (Saarni1997). The level of strain or stress that an individual is experiencing is a strong indicator of how they perceive their level of social support. When perceptively large stressors are present in a person's life, they tend to perceive their social support as lacking unless the social support is immediately present in their life during the time of the stressor (Asgari 2016).

In the working environment, social interaction and relationships have been shown to mediate and reduce the negative effects of employment stressors, such as work overload and interpersonal conflict (Pooja, De Clercq, and Belausteguigoitia 2016). Individuals experiencing financial stressors were two times less likely to experience psychological distress when they had access to social support (Aslund, Larm, Starrin, and Nilsson 2014). Students who were the victims of bullying for their sexual orientation were less likely to externalize if they had access to social support (Williams, Connolly, Pepler, and Craig 2005). In general, there appears to be 
support for the effect that social support has on strain; social support has a negative effect on criminal behavior. This relationship is particularly strong for females, who indicate that after experiencing certain stressors, high levels of social support reduce their likelihood of participating in criminal/deviant behaviors (Robbers 2004).

\section{Gender}

How an individual reacts to strain varies by gender. The current literature provides two arguments regarding strain and gender: 1) that both genders experience emotions to strain similarly and then cope similarly or 2) that males and females experience different emotions to strain, thus resulting in differing coping strategies. Research by Posick, Farrell, and Swatt (2013) indicates support for the first argument. While they found partial support for the mediating relationship of anger for males and depression for females, they also found that both emotions mediated the relationship between strain and deviance for either gender. Males and females were equally likely to respond externally and internally in the form of either violence or cutting. However, this study only focused on high school students and does not take into consideration other life stressors that occur after high school. In general, they noted that males are more likely to be reactive to strain than females (Lowe and May 2011).

Other research supports the second argument. According to Jang (2007), women experience strains related to physical health, interpersonal relations, and their gender roles in the family. Men were more likely to experience work-related and job strain. Due to the type of strains they identified, women were less likely to resort to criminal coping, and instead internalized their emotions in the form of anxiety or depression. Men experienced the otherdirected emotion - anger - which was more likely to result in deviant coping, while the women directed their internalized emotions towards legitimate coping (Jang 2007). 
Broidy and Agnew (1997) also found support for the argument that males and females experience different types of strains. In their work, they found that females were more likely to be exposed to network strains, gender-based discrimination, disproportionate demands from their peers, and low prestige in various areas in their life. For males, strain was thought to come from financial issues, interpersonal conflict, and criminal victimization. Both males and females experience anger in response to strain, but when females were exposed to strain, their anger came with depression, guilt, or anxiety. Males were also found to be outwardly aggressive, while females took out the conflict by becoming self-deprecating (Broidy and Agnew 1997).

\section{Theoretical Model}

Based on the literature in social psychology on feel bad, do good, as well as Agnew's (1992) GST, I propose a Strain Model of Criminal and Prosocial Behaviors (see Figure 2). Currently, the literature states that an individual's access to social support influences their likelihood of participating in criminal versus noncriminal coping (Agnew 1997; Agnew 2001; Cohen and Wills 1985). The present study focuses on social support because it is an adaptation that exists outside of the individual. While there are other resources for coping, to keep things concise, this research will be limited to only one form: social support. By focusing on four different types of strain (economic, interpersonal, victimization, and academic), this research will attempt to determine if different strains lead to different negative emotions, which in turn lead to either criminal coping or helping behavior (Botchkovar and Broidy 2013). It is anticipated that external strain may lead to helping behaviors because the literature on feel bad, do good indicates that individuals will help when they are put in a depressed or sad mindset (Cialdini and Kenrick 1976; Forest, Clark, Mills, and Isen 1979). 
Figure 1: General Strain Model (Adapted from Agnew 1992; Lee and Cohen 2008)

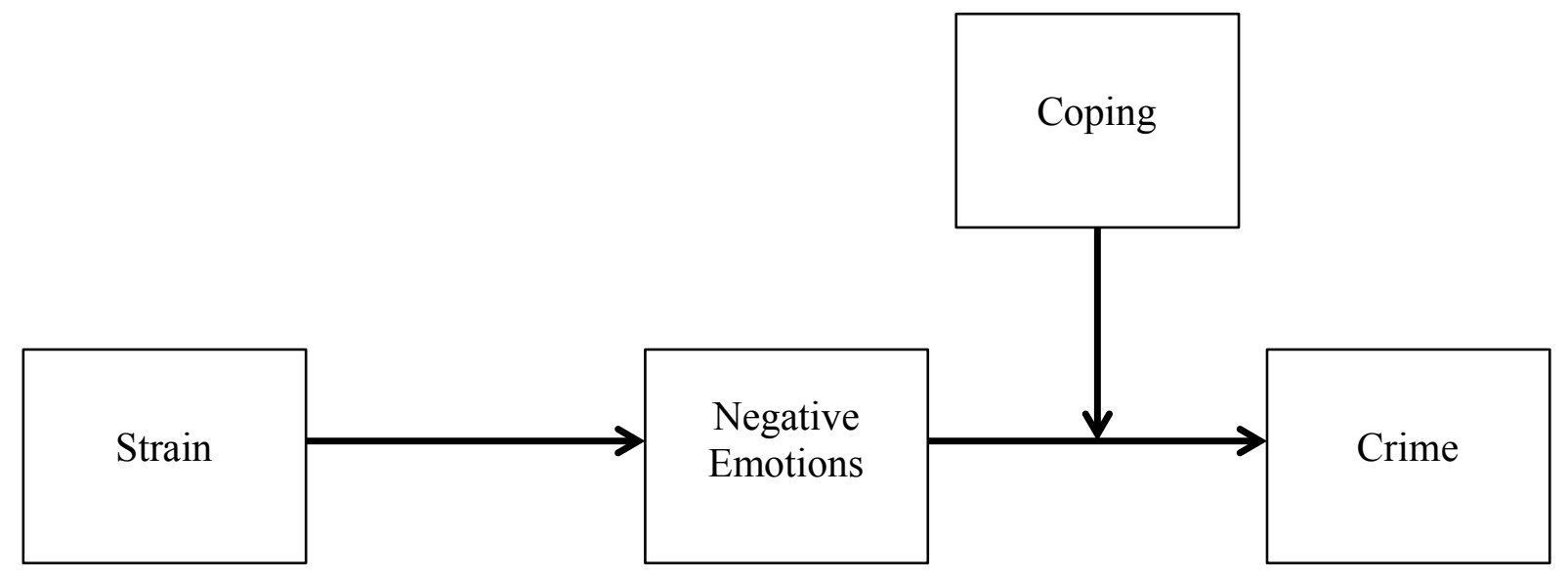

Figure 2: Strain Model of Criminal and Prosocial Behaviors

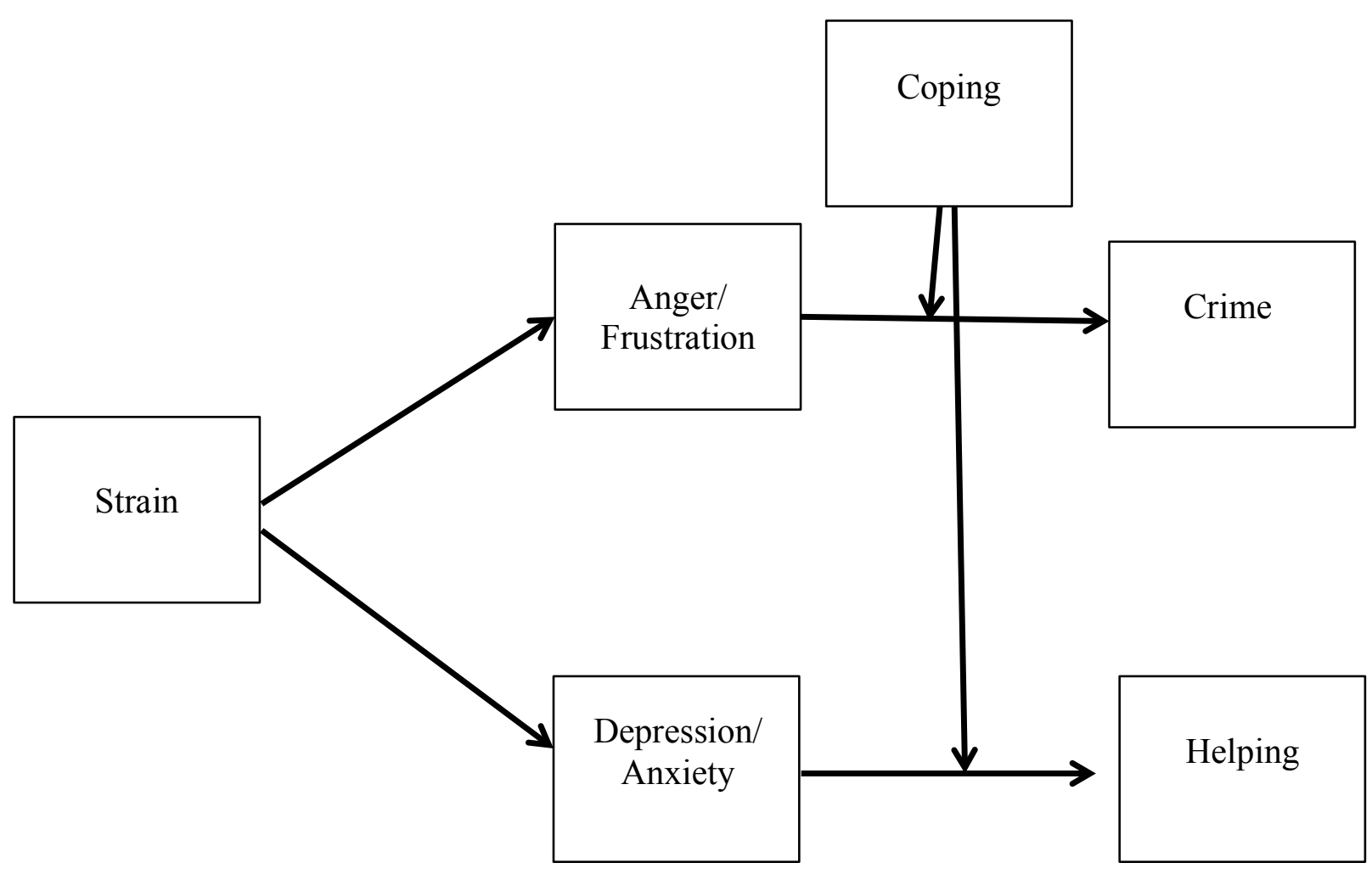




\section{METHODS}

To test whether strainful experiences can lead to prosocial rather than deviant behavior, a vignette experiment was used. Participants were provided a scenario that put them in the mindset of experiencing one of four types of strain: interpersonal, financial, victimization, or academic. The respondents then answered questions to gauge if the scenarios put them in a strained mindset, items targeted at measuring anger/frustration versus depression/anxiety in response to the scenario, their actual experiences with strain of that type and their actual responses, their responses to any stressful situation, their perceptions of social support, a slider bar activity to measure prosocial inclination, and demographic information.

\section{Stimuli}

Four common themes in the strain literature are interpersonal issues, financial problems, victimization, or academic stressors, which lead to strain (Botchkovar and Broidy 2013). To make it easier for individuals to put themselves in the mindset, they were presented a scenario, or vignette, describing one of the four types of strain. Interpersonal strain was framed with a scenario about the respondent experiencing conflict with their close friends, colleagues, or family. Financial strain was portrayed in a vignette about the respondent being unable to pay their bills (rent). The victimization strain was described in a case that discussed the respondent being physically attacked or threatened by a stranger. These cases were adapted from Botchkovar and Broidy (2013) who studied the additive effects of strain. They were also chosen because these types of strain appear to be common in the literature (Aslund, Larm, Starrin, and Nilsson 2014; Pooja, De Clercq, and Belausteguigoitia 2016; Williams, Connolly, Pepler, and Craig 2005). The academic strain scenario was modeled off of research done by Jun and Choi (2015), and describes a student who is struggling with a college-required course (See Appendix A). 


\section{Independent Variables}

Strain. Once the respondents read any of the vignettes, they responded to five 10-point Likert scale ( $1=$ strongly disagree to $10=$ strongly agree) questions pulled from the Psychological Strain Scales (Zhang and Lyu 2014). Items were chosen from these scales because they have been tested for reliability and validity and have yielded results indicating that the scales are adequate. The items measure varying sources of strain to determine if the respondents believe they are experiencing strain after they have read their scenario (See Appendix B).

Negative Emotions. Affective responses to strain were measured using items from Jang and Song's (2015) test of the coping process of Agnew's (1992) GST. Their use of the affective models was used to determine if type of affect led to either criminal or noncriminal coping. The anger scale had a Cronbach's alpha of 0.77 , which is just below the acceptable level of 0.80 . The depression scale had a Cronbach's alpha of 0.86 , which is adequate and thus indicates that both scales would be acceptable to utilize for examining the negative affects of respondents. Items that measure anger/frustration include "I sometimes feel like physically aggressing against others," or "If I get upset, I might hit someone." The scale for depression/anxiety consists of items similar to the following, "I worry about everything," or "I sometimes feel very sad with no particular reason." Items are measured on Likert scales ranging from 1 being strongly disagree and 10 being strongly agree (See Appendix C).

Social Support. The shortened version of the Social Support Questionnaire by Sarason, Sarason, Shearin, and Pierce (1987) was modified for the purposes of this survey. The original version of the survey had respondents indicate the person that provides them social support and then follow up with their level of satisfaction with that social support. My modification of the survey uses a ten-point Likert scale with 1 meaning strongly disagree and 10 meaning strongly 
agree to indicate their level of agreement of having that type of social support in their life. This survey was chosen because it was tested for reliability and was utilized in studies that measured the effects of stressful life events (similar to strain) and their social support. This scale was also particularly attractive because it appears to adequately measure social support in six short questions. The questions are targeted at measuring the respondent's access to someone that he or she can count on, specifically when the respondent is stressed or generally not feeling well (See Appendix D).

\section{Dependent Variables}

Items for how the individual responds to strain measure criminal coping versus helping behavior. Items measuring criminal coping were pulled from Antonaccio, Smith, and Gostjev (2015), who tested Merton's anomie theory and measured how relative strain led to projected delinquency. The items are broad, yet simple and should yield responses that indicate criminal coping, were it to happen. All questions are measured on a ten-point Likert scale from strongly disagree (1) to strongly agree (10). To measure an individual's attitudes towards helping, five items were pulled from Nickell's (1998) Helping Attitudes Scale. The five items chosen from the scale were selected because they reflected an individual's feelings towards helping others and how it would make them feel good. These items are also on a ten point Likert scale of agreement (See Appendix E).

\section{Additional Measures}

To ensure that individuals were going to behave in the manner they indicated on the survey, respondents were asked about their actual experiences with similar strains to see if their actual responses matched what they expected their behaviors to be in the scenario. Options pertaining to interpersonal stressors focused on instances when the respondent had experienced 
strain with a friend or acquaintance. Types of stressors included being lied to or having rumors spread about the respondent (Consiglio 2014). Items for financial strain came from research by Son and Wilson (2015), who found that most financial strain occurs when individuals cannot pay bills or provide for him or herself. Victimization items pertain to the findings of Baron (2004) and range from experiencing bullying to being robbed. Finally, experience with academic strain measured experience with getting a bad grade to failing a class as per research by Jun and Choi (2015) (See Appendix F).

A slider bar activity was placed towards the end of the survey to determine social value orientation. The purpose of the task was to determine if respondents were more prosocial or more proself to see if individuals indicating they would be more likely to participate in helping behaviors are predisposed to help. Respondents were given a prompt explaining that they were paired with a random person and were responsible for allocating resources between themselves and that random other. They were told to keep in mind that their decisions could result in them receiving money for themselves and the other person. The point of the task is to determine if the person is more altruistic, prosocial, individualistic, or competitive (Murphy, Ackerman, and Handgraaf 2011) (See Appendix G).

\section{RESULTS}

Since the causal argument in the Strain Theory Model of Criminal and Prosocial Behaviors theory is sequential - strains occur first, which then lead to negative emotions and subsequently crime or prosocial behaviors - path analysis is utilized. This type of analysis is ideal for instances in which a theory predicts a series of relationships believed to occur in a particular order (Acock 2013). I analyze two types of path models: one with social support as a moderator, as stated in Agnew's (1992) GST and in Figure 2, as well as a model with support as a mediator, 
which is the traditional framework for a path model. For each of the four types of strain a path diagram of the best fitting theoretical and empirical model are visually presented with standardized coefficients listed. In all path models I begin with the baseline model presented in Figure 2, adding a covariance relationship between the negative emotions of anger/frustration and depression/anxiety since previous research has shown it is entirely possible for the same strainful situation to result in multiple types of negative emotions (Broidy 2001). I also add a covariance between each moderating term (Anger/Frustration*Social Supprt; Depression/Anxieity*Social Support) and the social support variable (see Ping [2009] for this recommendation).

Once models were estimated, goodness-of-fit statistics were obtained to assess how well the theoretical model fit the empirical data. Modification indices were used to determine if the overall fit of the model could be enhanced. These indices are based on Lagrange multiplier tests and a significant test suggests that an omitted path should be added to the model to improve overall fit. If any of the suggested modifications made theoretical sense, they were added to the original path model and the analysis was repeated until a final model was obtained. Tables that decompose the direct, indirect, and total effects in the path models are available in Appendices $\mathrm{H}$ and I.

\section{Moderated Path Analyses}

Academic Strain. It was theorized that academic strain would activate the negative emotions of anger/frustration, which would be moderated by social support and result in deviant behaviors. Results from this model show support for the relationship between strain and negative emotion. As academic strain increases, the negative emotions of anger/frustration significantly 
increase $(0.32, p=0.001)$. However, there was no significant relationship between anger/frustration and crime nor was this relationship moderated by social support.

It was also theorized that academic strain would activate the negative emotions of depression/anxiety, which would be moderated by social support and result in helping behaviors. Results from this model show support for the relationship between strain and depression and anxiety. As academic strain increases, the negative emotions of depression/anxiety significantly increase $(0.46, p<0.001)$. However, while social support is a significant predictor of helping $(0.37, p=0.003)$, it does not mediate the relationship between depression/anxiety and helping behaviors.

The fit statistics for this path model are mixed. The model $\chi^{2}$ and RMSEA are not reported because they are not available due to the interaction terms. The SRMR falls above the 0.08 cutoff criteria $(0.178)$ while the CFI value is above the recommended $0.90-0.95$ cutoff value (1.00). A check of modification indices recommends no further changes to the paths in the model. In sum, these findings indicate that academic strain can lead to both anger/frustration and depression/anxiety. However, they do not provide any support for the relationship between negative affect and physical response. Furthermore, social support does not moderate the relationship between anger/frustration and crime/deviance or the relationship between depression/anxiety and helping behavior. 


\section{Figure 3. Academic Strain Moderated Path Model}

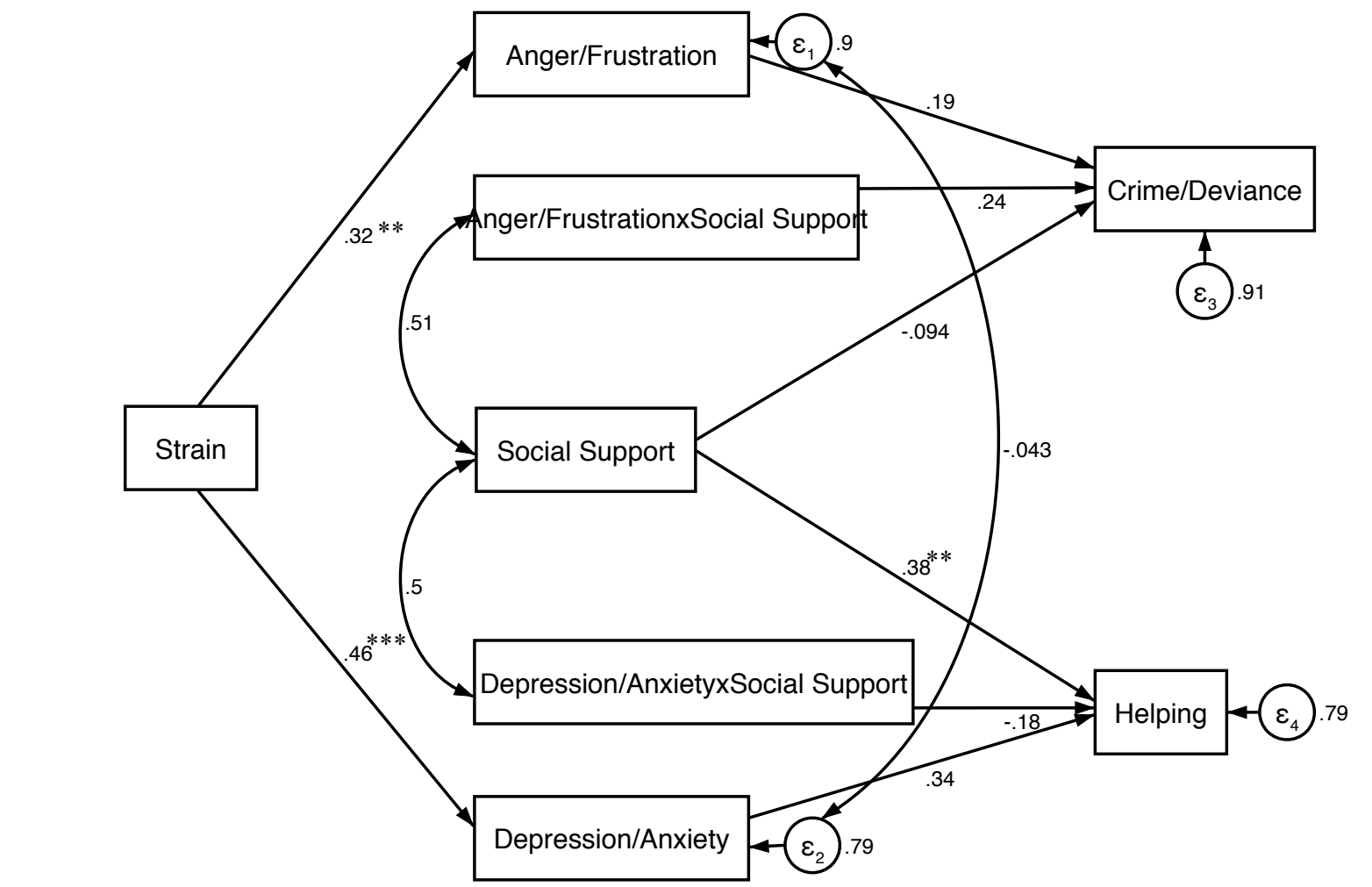

Notes: ${ }^{*} p<0.05 ; * * p<0.01 ; * * * p<0.001$ (two-tailed tests)

Interpersonal Strain. It was theorized that interpersonal strain would activate the negative emotions of anger/frustration, which would be moderated by social support and result in deviant behaviors. Results from this model show support for the relationship between strain and negative emotion. As interpersonal strain increases, the negative emotions of anger/frustration significantly increase $(0.38, p<0.001)$. Social support has a significant negative effect on crime/deviance $(-0.25, p=0.033)$ meaning that as social support levels increase, engagement in crime/deviance decrease. However, anger/frustration does not significantly impact crime/deviance and social support does not moderate this relationship.

It was also theorized that interpersonal strain would activate the negative emotions of depression/anxiety, which would be moderated by social support and result in helping behaviors. Results from this model show support for the relationship between strain and depression and 
anxiety. As interpersonal strain increases, the negative emotions of depression and anxiety significantly increase $(0.31, p=0.006)$. However, the model indicates that depression/anxiety is not significant to helping behavior, nor is this relationship moderated by social support.

The fit statistics for this path model are mixed. The model $\chi^{2}$ and RMSEA are not reported because they are not available due to the interaction terms. The SRMR falls above the 0.08 cutoff criteria $(0.228)$ while the CFI value is above the recommended $0.90-0.95$ cutoff value (1.00). A check of modification indices recommends no further changes to the paths in the model. In sum, these findings indicate that interpersonal strain can lead to both anger/frustration and depression/anxiety. However, they do not provide any support for the relationships between negative affect and physical response. Social support does not moderate the relationship between anger/frustration and crime/deviance, or between depression/anxiety and helping.

Figure 4. Interpersonal Strain Moderated Path Model

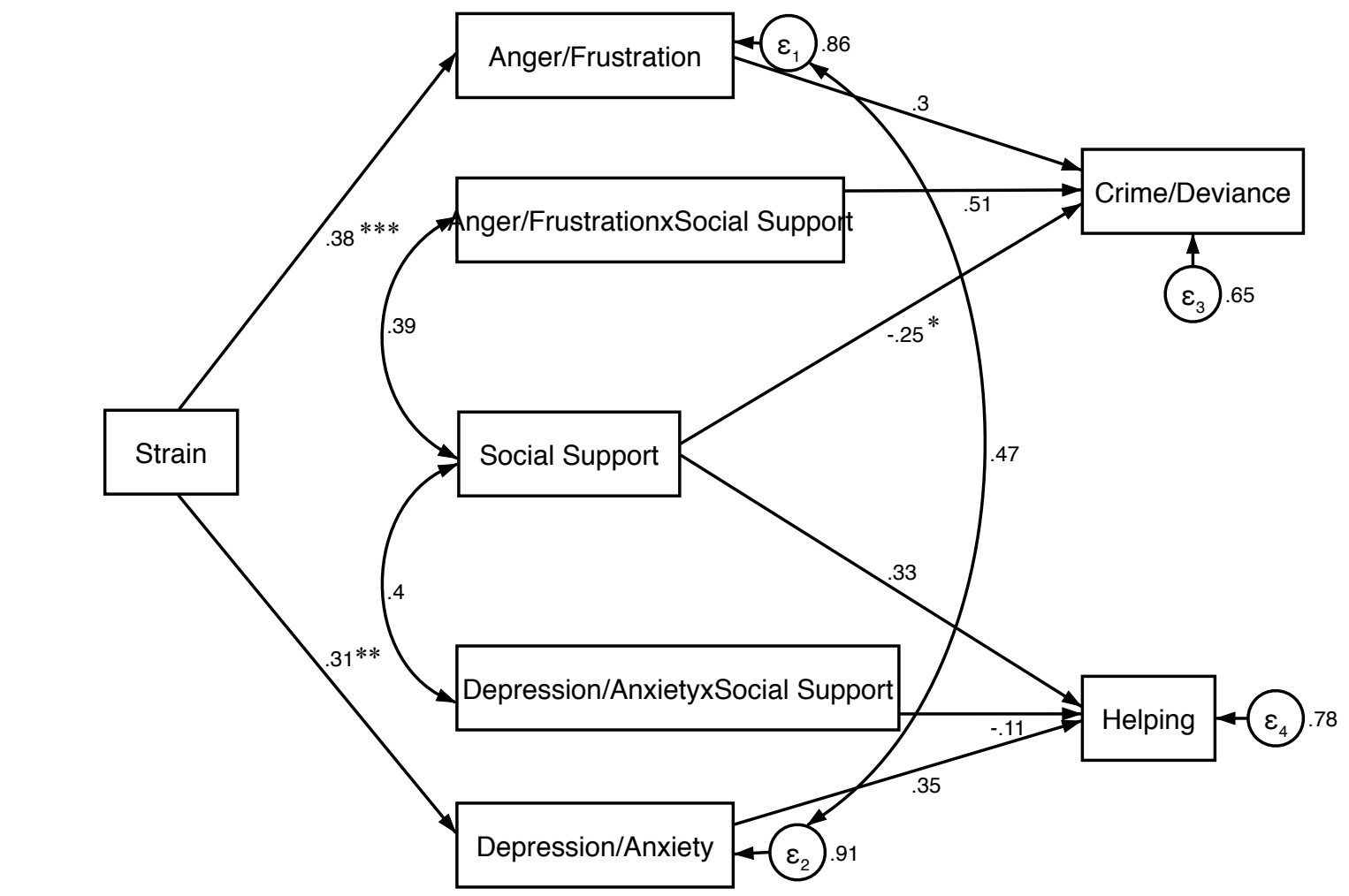

Notes: ${ }^{*} p<0.05 ; * * p<0.01 ; * * * p<0.001$ (two-tailed tests) 
Victimization Strain. It was theorized that victimization strain would activate the negative emotions of anger/frustration, which would be moderated by social support and result in deviant behaviors. Results from this model show support for the relationship between strain and those negative emotions. As victimization strain increases, the negative emotions of anger/frustration significantly increase $(0.32, p=0.002)$. Anger and frustration are not significant to crime $(0.14, p$ $=0.656)$ but are moderated by social support $(0.66, p=0.009)$. The following equation shows anger/frustration's moderated association with deviance: $a+b U$, where $a=$ the coefficient from anger/frustration to crime; $b=$ the coefficient from the interaction term of anger/frustration* ${ }^{*}$ social support to crime; and $U=$ social support (the moderator). Based on that information, $\mathrm{a}+\mathrm{bU}=0.140+0.664$ (social support). This equation indicates that social support amplifies the positive relationship between anger/frustration and crime. As anger and frustration increase, crime increases (0.140), but increases in social support make this relationship even more positive (0.664).

It was also theorized that victimization strain would activate the negative emotions of depression/anxiety, which would be moderated by social support and result in helping behaviors. Results from this model do not show support for the relationship between strain and depression and anxiety $(0.20, p=0.08)$. However, social support is significant to helping $(0.57, p=0.001)$. Depression/anxiety are not significant to helping $(0.35, p=0.295)$ and are not moderated by social support $(-0.30, p=0.452)$.

The fit statistics for this path model are mixed. The model $\chi^{2}$ and RMSEA are not reported because they are not available. The SRMR falls above the 0.08 cutoff criteria $(0.262)$ while the CFI value is above the recommended $0.90-0.95$ cutoff value (1.00). A check of modification indices recommends no further changes to the paths in the model. 


\section{Figure 5. Victimization Strain Moderated Path Model}

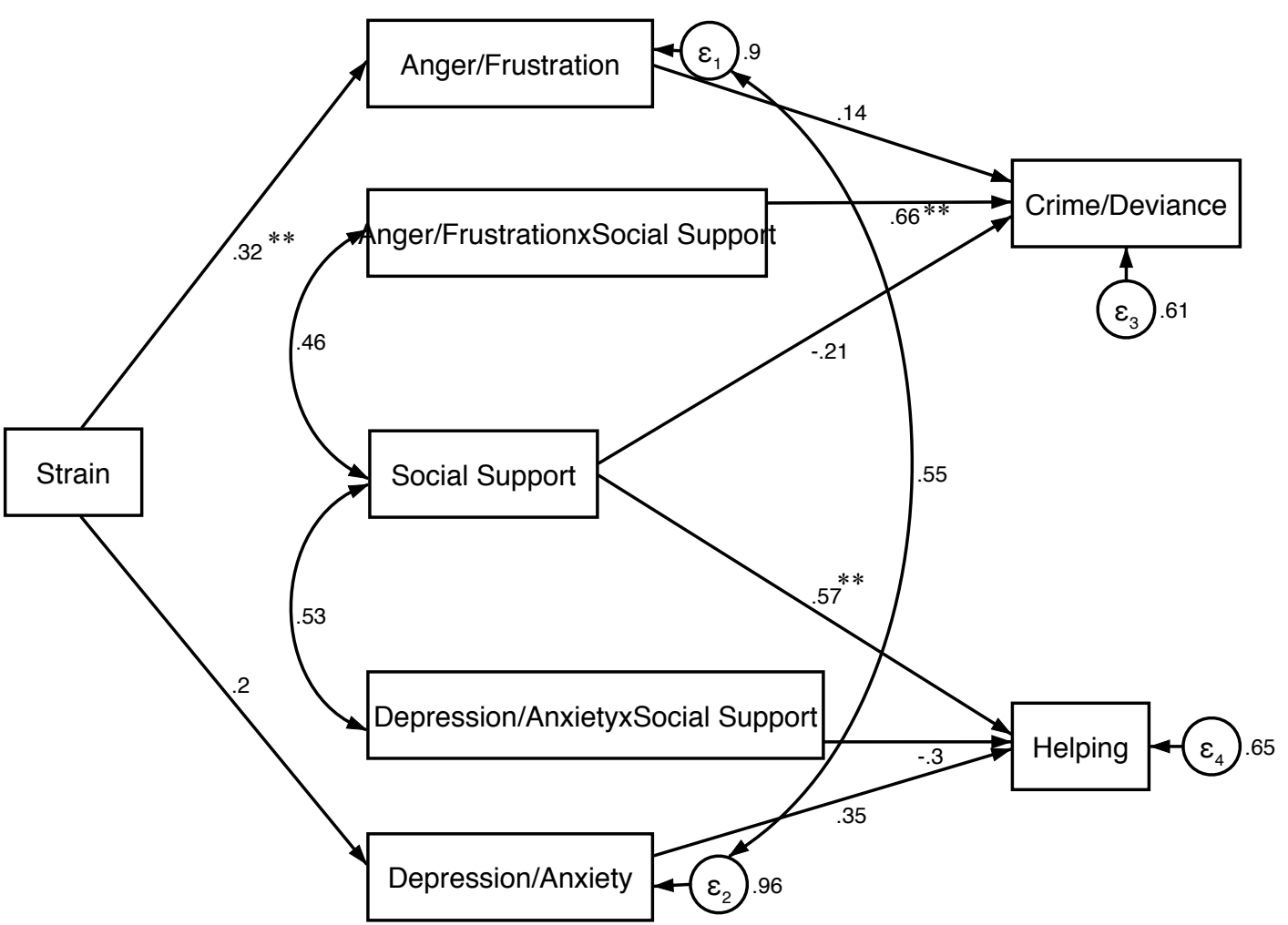

Notes: ${ }^{*} p<0.05 ; * * p<0.01 ; * * * p<0.001$ (two-tailed tests)

Financial Strain. It was theorized that financial strain would activate the negative emotions of anger/frustration, which would be moderated by social support and result in deviant behaviors. Results from this model show support for the relationship between strain and those negative emotions. As financial strain increases, the negative emotions of anger/frustration significantly increase $(0.32, p=0.003)$. Anger/frustration are significant to crime $(0.57, p=$ $0.007)$ but are not moderated by social support $(0.17, p=0.595)$. Thus, increases in anger/frustration lead to an increase in deviant behavior, regardless of one's level of social support.

It was also theorized that financial strain would activate the negative emotions of depression/anxiety, which would be moderated by social support and result in helping behaviors. 
Results from this model do show support for the relationship between strain and depression/anxiety $(0.35, p=0.001)$. Social support is also significant to helping $(0.36, p=$ 0.037). Depression/anxiety are not significant to helping $(-0.27, p=0.096)$, however they are moderated by social support $(0.39, p=0.046)$. The following equation shows depression/anxiety's moderated association with helping: $a+b U$, where $a=$ the coefficient from depression/anxiety to helping; $b=$ the coefficient from the interaction term of depression/anxiety*social support to helping; and $\mathrm{U}=$ social support (the moderator). Based on that information, $\mathrm{a}+\mathrm{bU}=0.267+0.395$ (social support). Because a respondent's value on the social support scale is always a positive number greater than 1 , any value of social support that is put into the equation and multiplied by 0.395 will be greater than -0.267 . Therefore, this indicates that even though increases in depression and anxiety should decrease helping, as social support goes up, it counteracts that negative effect and increases helping.

The fit statistics for this path model are mixed. The model $\chi^{2}$ and RMSEA are not reported because they are not available. The SRMR falls above the 0.08 cutoff criteria $(0.217)$ while the CFI value is above the recommended $0.90-0.95$ cutoff value (1.00). A check of modification indices recommends no further changes to the paths in the model. 


\section{Figure 6. Financial Strain Moderated Path Model}

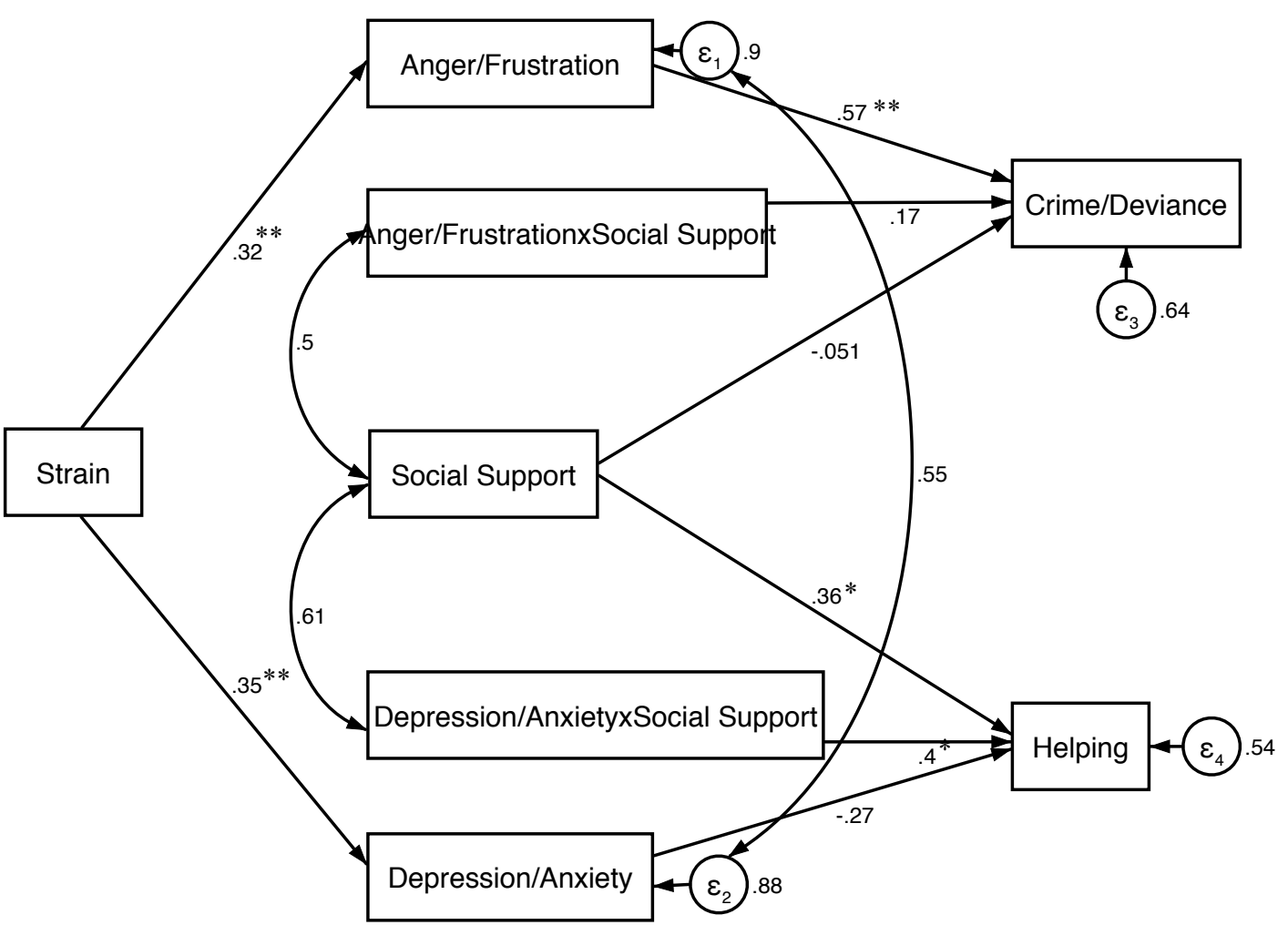

Notes: ${ }^{*} p<0.05 ; * * p<0.01 ; * * * p<0.001$ (two-tailed tests)

Academic Strain Moderator by Gender. Analyses were run for males and females separately using the academic strain model, as that model had the best fit and because previous literature indicated that males and females react differently to strain. It was theorized that academic strain would be more likely to activate the negative emotions of anger/frustration in males, which would result in deviant behaviors but be moderated by social support. Results from this model do not show support for the relationship between strain and those negative emotions in males. As academic strain increases, the negative emotions of anger/frustration do not appear to increase significantly $(-0.01, p=0.938)$. Social support, however, is significant to crime ($0.46, p=0.013)$, specifically increases in social support decrease engagement in crime/deviance. While anger and frustration is not significant to crime $(-0.11, p=0.607)$, it is moderated by 
social support $(0.78, p=0.022)$. The following equation shows anger/frustration's moderated association with crime: $\mathrm{a}+\mathrm{bU}$, where $\mathrm{a}=$ the coefficient from anger/frustration to crime; $\mathrm{b}=$ the coefficient from the interaction term of anxiety/depression*social support to crime; and $\mathrm{U}=$ social support (the moderator). Based on that information, $\mathrm{a}+\mathrm{bU}=-0.112+0.784$ (social support). Because a respondent's value on the social support scale is always a positive number greater than 1 , any value of social support that is put into the equation and multiplied by 0.784 will be greater than -0.112 . Therefore, this indicates that even though increases in anger/frustration should decrease deviance, as social support goes up, it counteracts that negative effect and actually increases criminal behavior.

Interestingly, males tend to experience depression/anxiety as a result of academic strain, which was not predicted based on previous literature. The experience of depression/anxiety should lead to helping behavior, which is moderated by social support. For males, as academic strain increases, the negative emotions of depression/anxiety significantly increase $(0.49, p=$ 0.003). This finding is interesting in that it is not a male stereotypical emotional response. Social support is not significant to helping $(0.18, p=0.536)$. Also, increases in depression and anxiety do not lead to a significant increase in helping behavior $(-0.12, p=0.736)$, nor is this relationship moderated by social support.

The fit statistics for this path model are mixed. The model $\chi^{2}$ and RMSEA are not reported because they are not available. The SRMR falls above the 0.08 cutoff criteria (0.195) while the CFI value is above the recommended $0.90-0.95$ cutoff value (1.00). A check of modification indices recommends no further changes to the paths in the model. 


\section{Figure 7. Academic Strain Moderated Path Model for Males}

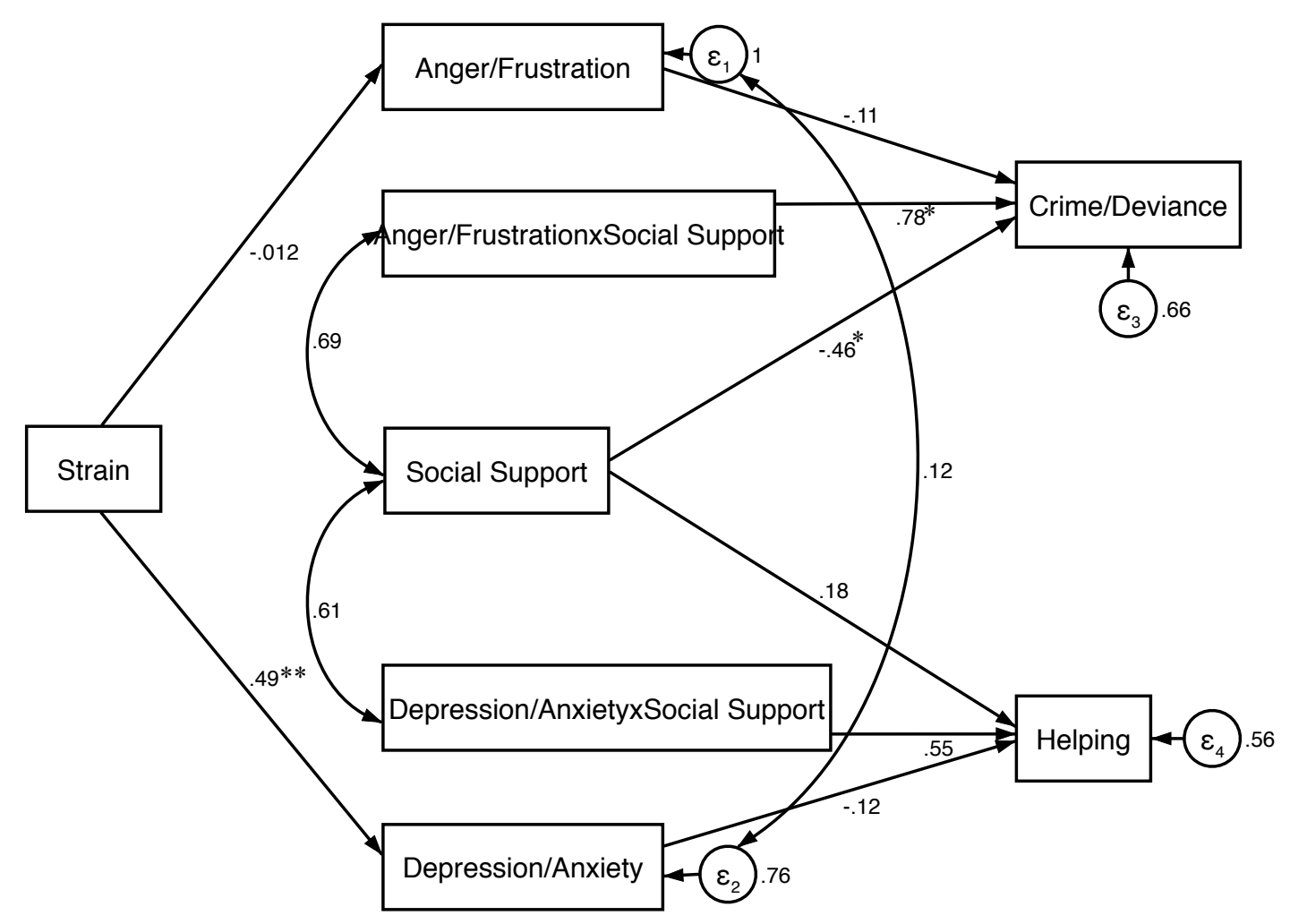

Notes: ${ }^{*} p<0.05 ;{ }^{* *} p<0.01 ;{ }^{* * *} p<0.001$ (two-tailed tests)

It was theorized that academic strain would be more likely to activate the negative emotions of depression and anxiety in females, which would result in helping behaviors but be moderated by social support. Females do experience depression/anxiety as a result of academic strain, supporting previous literature. As academic strain increases, the negative emotions of depression/anxiety increase significantly $(0.36, p=0.001)$. Social support is not significant to helping behavior $(0.22, p=0.423)$. Also, increases in depression and anxiety is not significant to helping behavior from females $(0.24, p=0.558)$, and is not moderated by social support $(-0.21, p$ $=0.666)$.

Contrary to what previous literature states, women also experience anger and frustration as the result of academic strain. As academic strain increases, the negative emotions of 
anger/frustration appear to increase significantly $(0.46, p<0.001)$. However, social support is not significant to crime/deviance for females $(0.09, p 0.329)$. Instead, increases in anger and frustration do lead to an increase in crime/deviance $(0.66, p<0.001)$, but this relationship is not moderated by social support.

The fit statistics for this path model are decent. The model $\chi^{2}$ and RMSEA are not reported due to interaction terms. The SRMR falls above the 0.08 cutoff criteria $(0.215)$, meanwhile the CFI value is above the recommended 0.90-0.95 cutoff value (1.00). A check of modification indices recommends no further changes to the paths in the model.

\section{Figure 8. Academic Strain Moderated Path Model for Females}

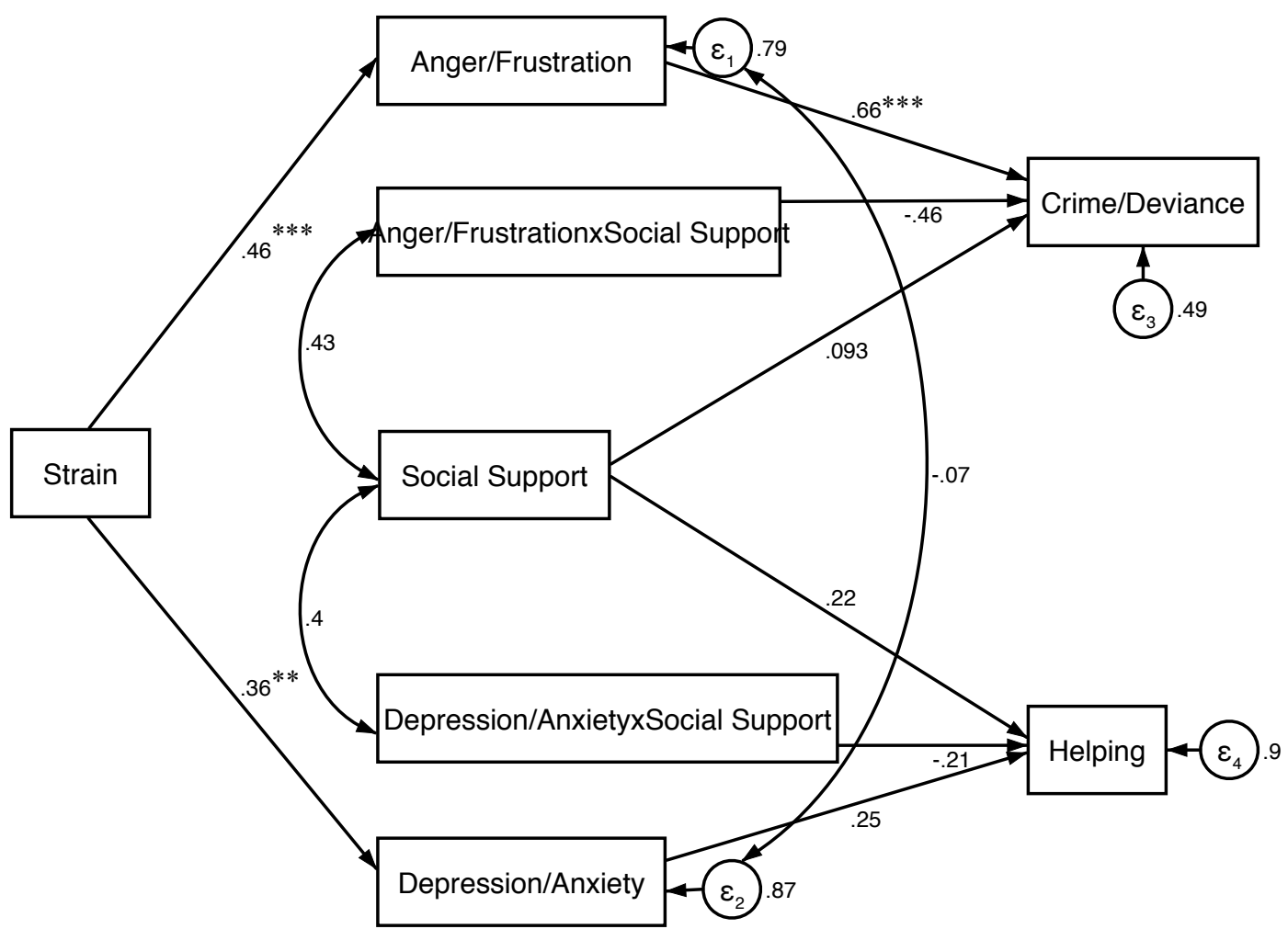

Notes: ${ }^{*} p<0.05 ;{ }^{* *} p<0.01 ;{ }^{* *} p<0.001$ (two-tailed tests)

Ancillary Analyses: Mediated Path Models

The results of social support as a moderator in the Strain Theory Model of Criminal and Prosocial Behaviors are mixed. In only three models did social support have a significant 
moderating effect on the relationship between negative emotions and crime or helping behaviorfinancial strain, victimization strain, and academic strain for males. Furthermore, in two of these models - academic strain for males and victimization - higher levels of social support amplified the effect of anger/frustration on crime. This means that individuals with higher levels of social support were more likely to commit criminal or deviant acts in response to higher feelings of anger/frustration. This relationship is exactly the opposite of what Agnew (1992) would predict. Social support is meant to decrease the relationship between anger/frustration and deviance by giving respondents a mechanism to help coping with negative emotions in a non-deviant manner.

In light of these findings, I propose a set of ancillary analyses that model social support as a mediator between negative emotions and behaviors. This alternative specification of the Strain Theory Model of Criminal and Prosocial Behaviors is illustrated in Figure 9. It may be the case that the experiences of negative emotions resulting from strain lead strained individuals to more heavily rely on social support systems prior to engaging in crime or helping behaviors. Thus, the mere presence of social support may not be a significant coping mechanism in dealing with strain, as initially suggested by Agnew (1992), but rather it is one's likelihood to actually call on social support when feeling strained that may actually decrease criminal actors or increase prosocial ones. Although the social support scale distributed in the vignette surveys may not full capture reliance on social support as much as the presence of social support systems, I provide at least a preliminary examination of the possible mediating role of social support in responses to strain. 


\section{Figure 9: Mediated Strain Model of Criminal and Prosocial Behaviors}

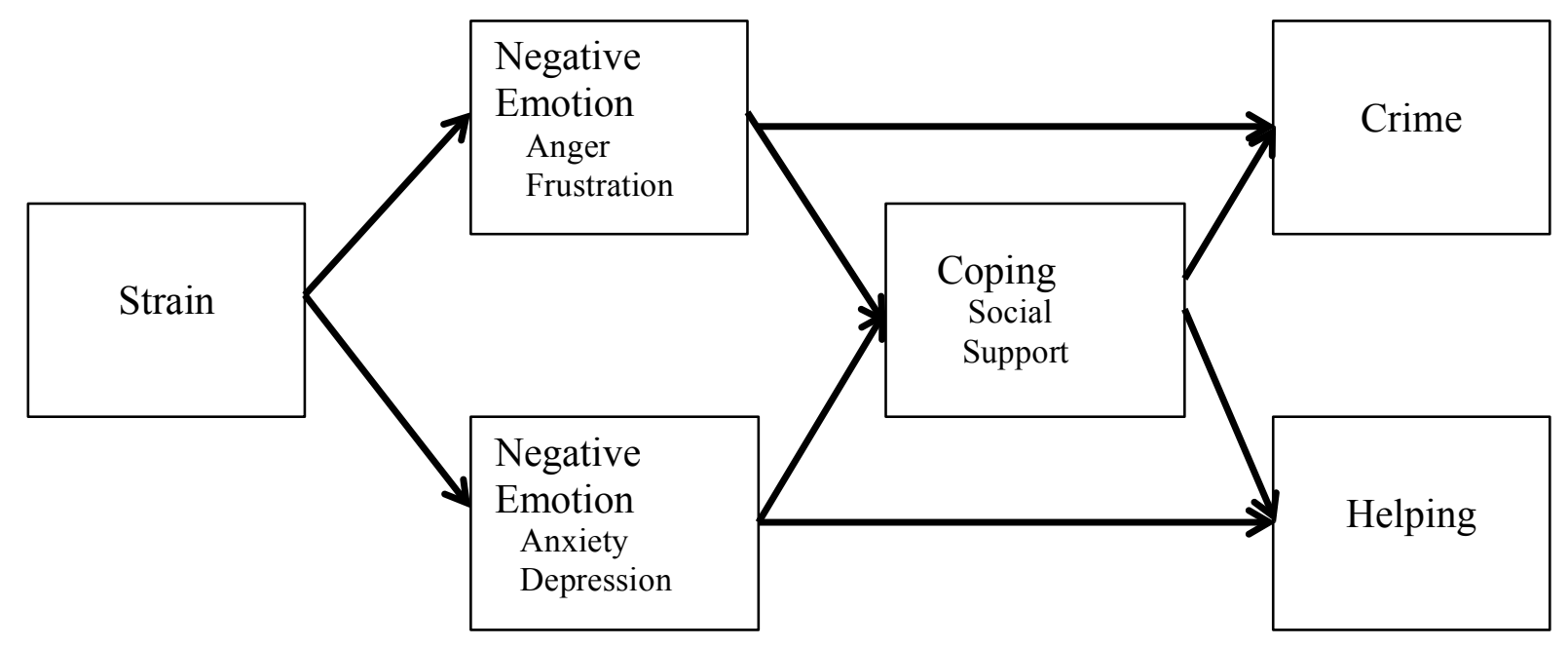

Academic Strain. It was theorized that academic strain would activate the negative emotions of anger/frustration, which would be mediated by social support and result in deviant behaviors. Results from this model show support for the relationship between strain and negative emotion. As academic strain increases, the negative emotions of anger/frustration significantly increase $(0.32, p<0.001)$. However, social support does not significantly mediate the relationship between anger/frustration and crime/deviance $(0.01, p=0.91)$. Instead, increases in anger and frustration lead directly to an increase in crime/deviance $(0.37, p=0.002)$.

It was also theorized that academic strain would activate the negative emotions of depression/anxiety, which would be mediated by social support and result in helping behaviors. Results from this model show support for the theoretical model and indicate that as academic strain increases, the negative emotions of depression/anxiety also increase significantly $(0.46, p$ $<0.001)$. Social support does significantly mediate the relationship between anxiety and depression and helping behavior $(0.30, p=0.002)$. Also, increases in anxiety and depression leads to a significant increase in helping behaviors $(0.20, p=02)$. 
These findings support the relationship from strain to crime. However, they also support the relationship from strain to helping. While social support does not impact the relationship between anger/frustration and crime/deviance, it does improve the relationship between depression/anxiety and helping behavior.

The fit statistics for this path model are also excellent. The model $\chi^{2}$ is not significant $(6.22, p=0.399)$. Both the RMSEA and SRMR fall below the 0.08 cutoff criteria (0.02 and 0.04, respectively) while the CFI value is above the recommended $0.90-0.95$ cutoff value $(0.99)$. A check of modification indices recommends no further changes to the paths in the model.

\section{Figure 10. Academic Strain Mediated Path Model}

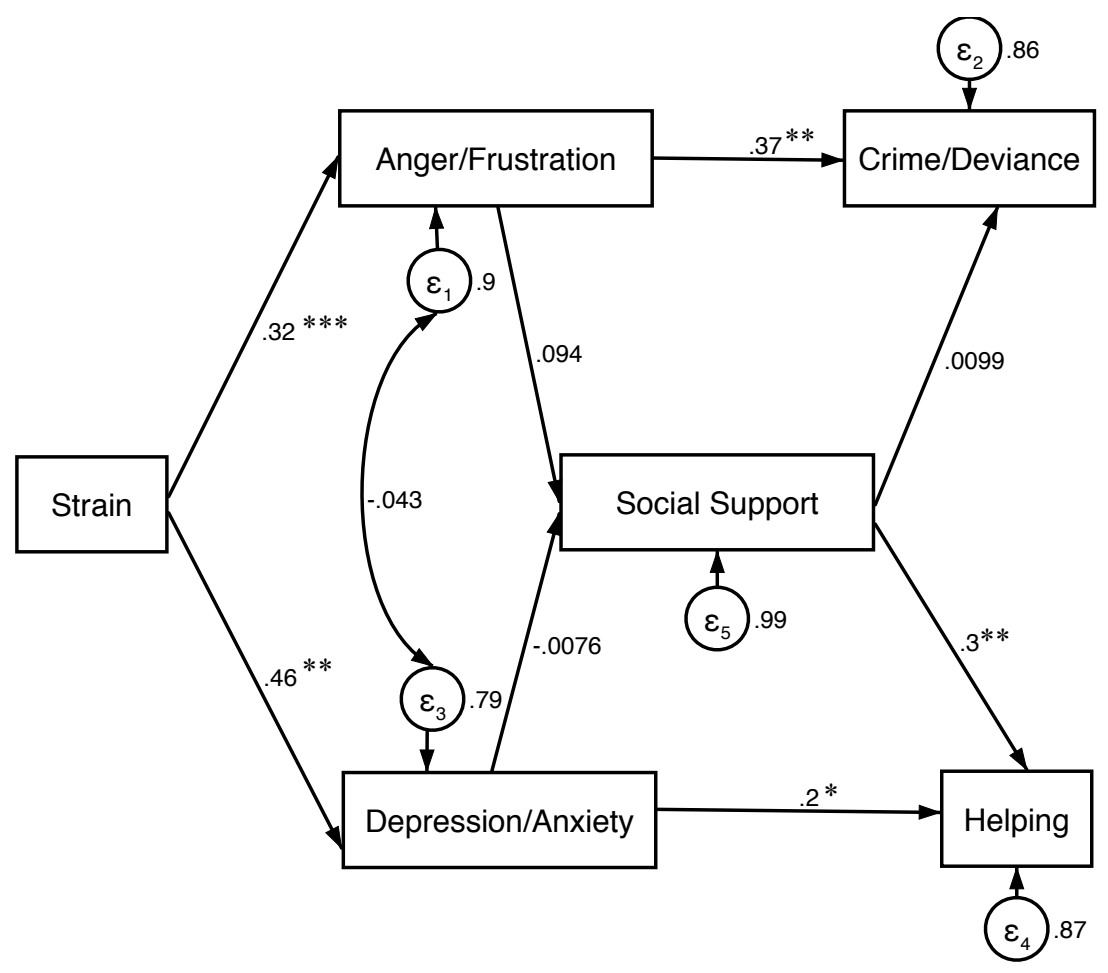

Notes: ${ }^{*} p<0.05 ; * * p<0.01 ; * * * p<0.001$ (two-tailed tests) 
Interpersonal Strain - Initial Path Model. It was theorized that interpersonal strain would also activate the negative emotions of anger/frustration, which would be mediated by social support and result in deviant behaviors. Results from this model show support for the relationship between strain and negative emotion. As interpersonal strain increases, the negative emotions of anger/frustration increase significantly $(0.38, p<0.001)$. However, social support does not significantly mediate the relationship between anger/frustration and crime/deviance ($0.02, p=0.80)$. Instead, increases in anger and frustration do lead to a significant increase in crime/deviance $(0.67, p<0.001)$.

It was also theorized that interpersonal strain would activate the negative emotions of depression/anxiety, which would be mediated by social support and result in helping behaviors. Results from this model show support for the theoretical model and indicate that as interpersonal strain increases, the negative emotions of depression/anxiety also significantly increase $(0.31, p$ $=0.004)$. Social support does significantly mediate the relationship between anxiety and depression and helping behavior $(0.29, p=0.013)$. Also, increases in anxiety and depression lead to an increase in helping behaviors $(0.27, p=0.013){ }^{2}$

These findings support the relationship from strain to crime. The findings also support the relationship from strain to helping and the relationship from depression and anxiety to social support. The findings support the relationship of depression and anxiety to helping as well. Social support does not impact the relationship between anger/frustration and crime/deviance.

The fit statistics for this initial path model are poor. The model $\chi^{2}$ is significant $(25.70, p$ $<0.001)$. Both the RMSEA and the SRMR fall above the 0.08 cutoff criteria $(0.18$ and 0.11 , respectively), while the CFI value falls below the recommended 0.90-0.95 cutoff value (0.85). A

\footnotetext{
${ }^{2}$ Note that this initial relationship between anxiety and depression and helping behaviors it not reflected in Figure 4 since this figure only presents the final path model discussed in more detail below.
} 
check of modification indices recommends adding direct paths in the model from anger/frustration to helping to significantly increase the fit of the initial path model.

Modified Path Model. This model adds a direct path between anger/frustration and helping as suggested by the modification indices. Note that such a direct link between those specific negative emotions and helping was not hypothesized by GST or previous literature. Adding these direct paths from anger/frustration to helping does not affect the significant effects of anger/frustration and deviance. The coefficients and levels of statistical significance for these variables are the same as the initial path model since I did not alter this part of the model.

The added path from anger/frustration to helping is statistically significant $(0.39, p$ $<0.01)$. However, the added path from anger and frustration to helping removed the significant relationship between depression and anxiety and helping $(0.06, p=0.59)$. By adding this direct path, the fit of the modified path model has significantly increased. The model $\chi^{2}$ is still statistically significant, but at a lower level $(12.36, p=0.03)$. The RMSEA is still above the 0.08 cutoff criteria (0.12) but the SRMR is now below the cutoff criteria $(0.07)$. The CFI is also now within the recommended 0.90-0.95 cutoff range (0.945). 


\section{Figure 11. Interpersonal Strain Mediated Path Model}

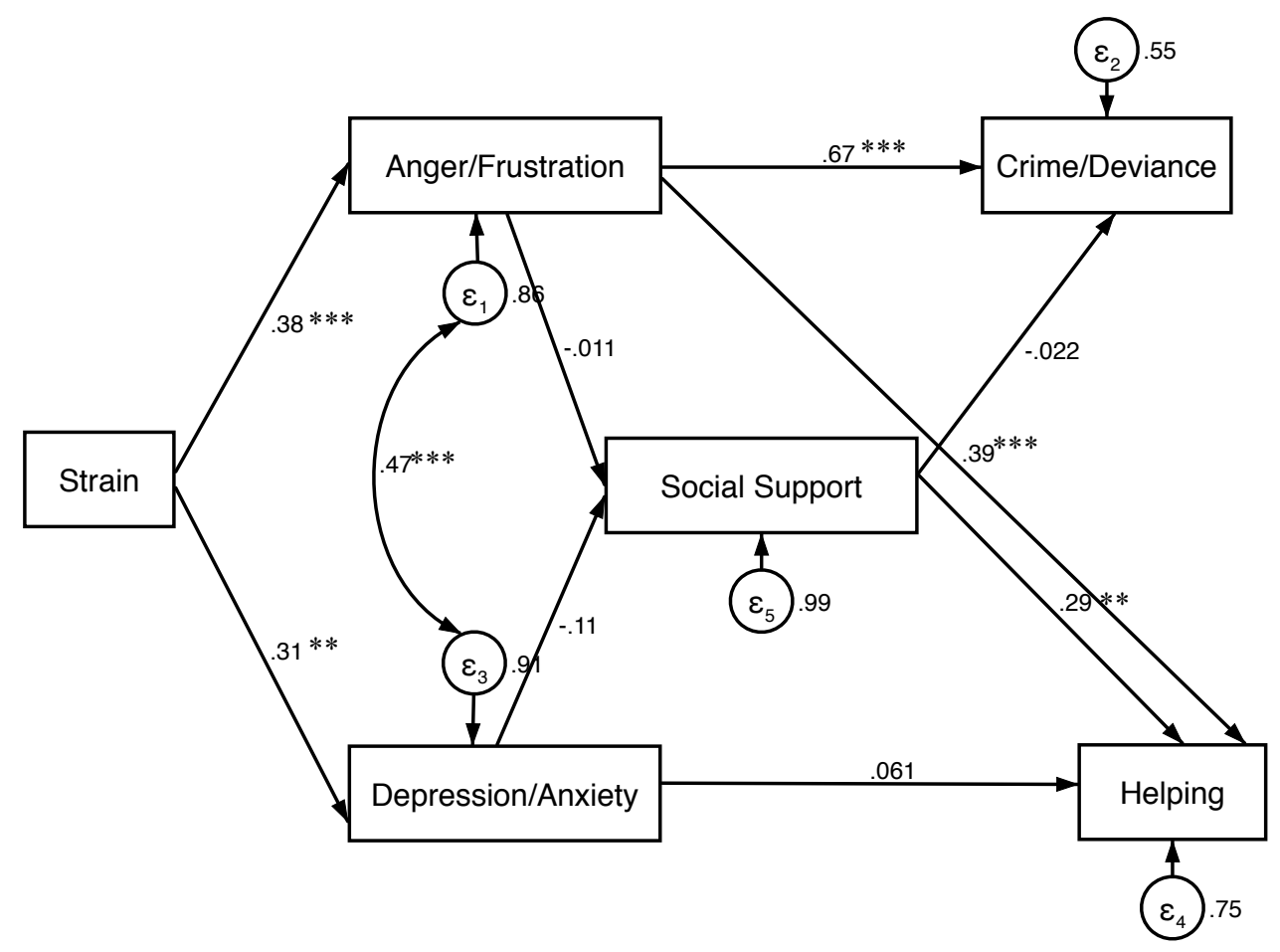

Notes: ${ }^{*} p<0.05 ; * * p<0.01 ; * * * p<0.001$ (two-tailed tests)

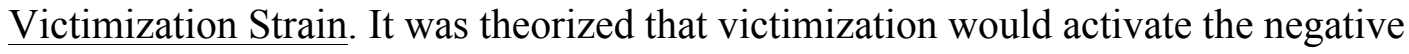
emotions of anger/frustration, which would be mediated by social support and result in deviant behaviors. Results from this model show statistically significant support for the relationship between strain and negative emotion. As victimization strain increases, the negative emotions of anger/frustration increase $(0.32, p=0.001)$. However, social support does not mediate the relationship between anger/frustration and crime/deviance $(0.10, p=0.251)$. Instead, increases in anger and frustration do lead to an increase in crime/deviance $(0.66, p<0.01)$.

It was also theorized that victimization strain would activate the negative emotions of depression/anxiety, which would be mediated by social support and result in helping behaviors. Results from this model do not show support for the theoretical model and therefore do not 
indicate that as victimization strain increases, the negative emotions of depression/anxiety also increase $(0.20, p 0.07)$. Social support does significantly mediate the relationship between anxiety and depression and helping behavior $(0.47, p<0.01)$. However, increases in anxiety and depression do not lead to a significant increase in helping behaviors $(0.11, p=0.27)$.

These findings support the relationship from strain to crime. However, they do not provide support for the relationship between strain and depression/anxiety. They do provide support for the mediating impact of social support on the relationship between depression/anxiety and helping behavior. The findings fail to indicate a relationship between depression/anxiety and helping. Social support does not impact the relationship between anger/frustration and crime/deviance.

The fit statistics for this path model are also poor. The model $\chi^{2}$ is statistically significant (24.66, $p<0.00)$. Both the RMSEA and SRMR fall above the 0.08 cutoff criteria $(0.17$ and 0.08 , respectively) while the CFI value is below the recommended $0.90-0.95$ cutoff value $(0.88)$. A check of modification indices recommends no further changes to the paths in the model. 
Figure 12. Victimization Strain Mediated Path Model

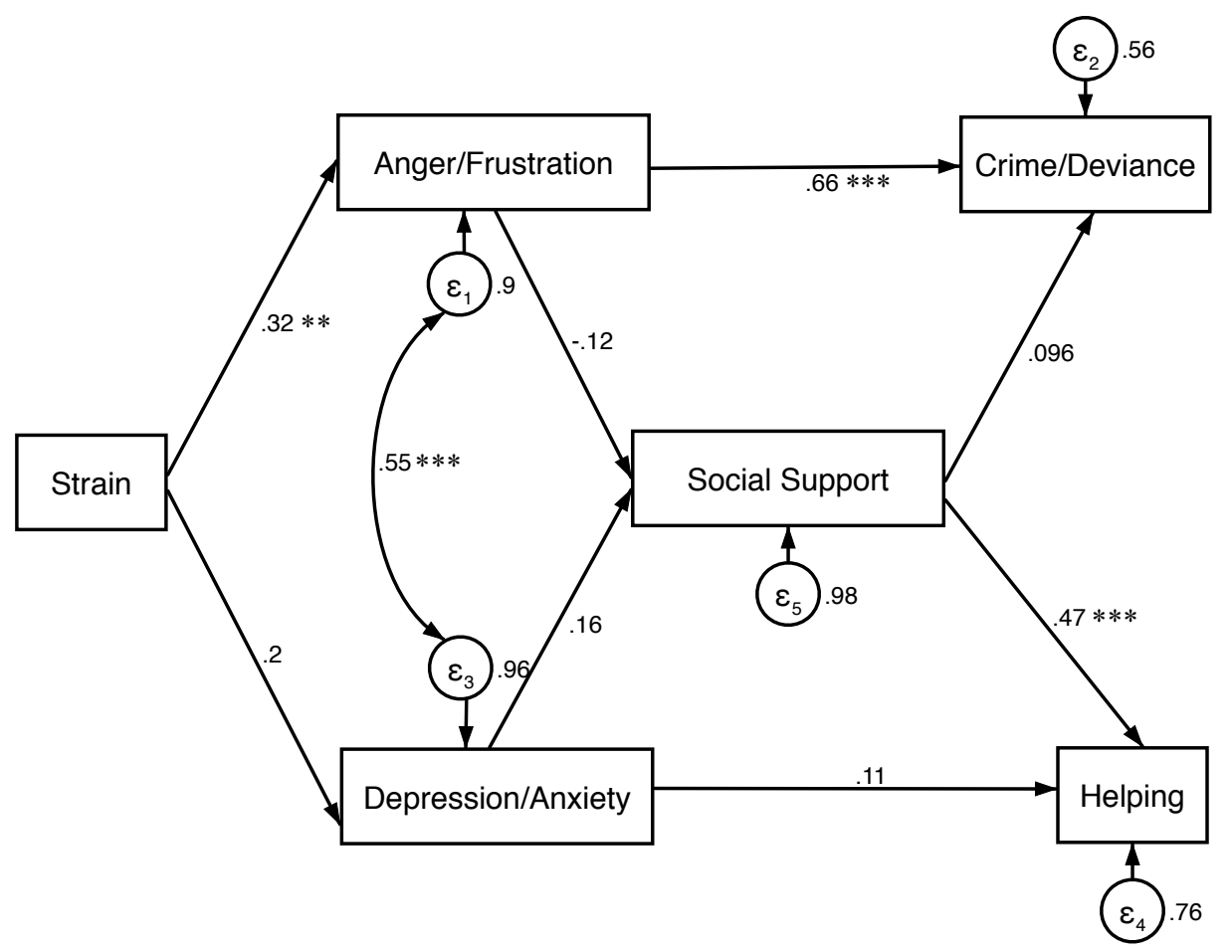

Notes: ${ }^{*} p<0.05 ; * * p<0.01 ; * * * p<0.001$ (two-tailed tests)

Financial Strain - Initial Path Model. It was theorized that financial strain would also activate the negative emotions of anger/frustration, which would be mediated by social support and result in deviant behaviors. Results from this model show support for the relationship between strain and negative emotion. As financial strain increases, the negative emotions of anger/frustration significantly increase $(0.32, p=-.002)$. However, social support does not significantly mediate the relationship between anger/frustration and crime/deviance $(0.02, p=$ 0.80). Instead, increases in anger and frustration do lead to a significant increase in crime/deviance $(0.66, p<0.001)$.

It was also theorized that financial strain would activate the negative emotions of depression/anxiety, which would be mediated by social support and result in helping behaviors. 
Results from this model show significant support for the theoretical model and indicate that as financial strain increases, the negative emotions of depression/anxiety also increase $(0.35, p=$ 0.001). Social support does mediate the relationship between anxiety and depression and helping behavior $(0.61, p<0.01)$. Unfortunately, increases in anxiety and depression do not lead to an increase in helping behaviors $(0.05, p=0.70)$.

These findings support the relationship from strain to crime. However, they do not support the relationship from strain to helping. Financial strain leads to anxiety and depression. Depression/anxiety and helping are mediated by the effects of social support. Depression and anxiety do not lead to helping behavior, however. Social support does not impact the relationship between anger/frustration and crime/deviance, but it does improve the relationship between depression/anxiety and helping behavior.

The fit statistics for this path model are poor. The model $\chi^{2}$ is significant $(59.23, p<$ 0.001). Both the RMSEA and the SRMR fall above the 0.08 cutoff criteria $(0.29$ and 0.15 , respectively), while the CFI value falls below the recommended $0.90-0.95$ cutoff value (0.76). A check of modification indices recommends adding direct paths in the model from anger/frustration to helping to significantly increase the fit of the initial path model, as it did in the interpersonal strain path model.

Modified Path Model. This model adds the direct path between anger/frustration and helping. Note that such a direct link between those specific negative emotions and helping was not hypothesized by GST or previous literature. Adding these direct paths from anger/frustration to helping does not affect the significant effects of anger/frustration and deviance. The coefficients and levels of statistical significance for these variables are the same as the initial path model since I did not alter this part of the model. 
The added path from anger/frustration to helping is statistically significant $(0.30, p$ $<0.01$ ). By adding this direct path, the fit of the modified path model has increased significantly. The model $\chi^{2}$ is still statistically significant, but at a lower level $(48.58, p<0.001)$. The RMSEA and SRMR are both still above the 0.08 cutoff criteria ( 0.28 and 0.13 , respectively). The CFI is also still below the recommended 0.90-0.95 cutoff range ( 0.81$)$.

\section{Figure 13. Financial Strain Mediated Path Model}

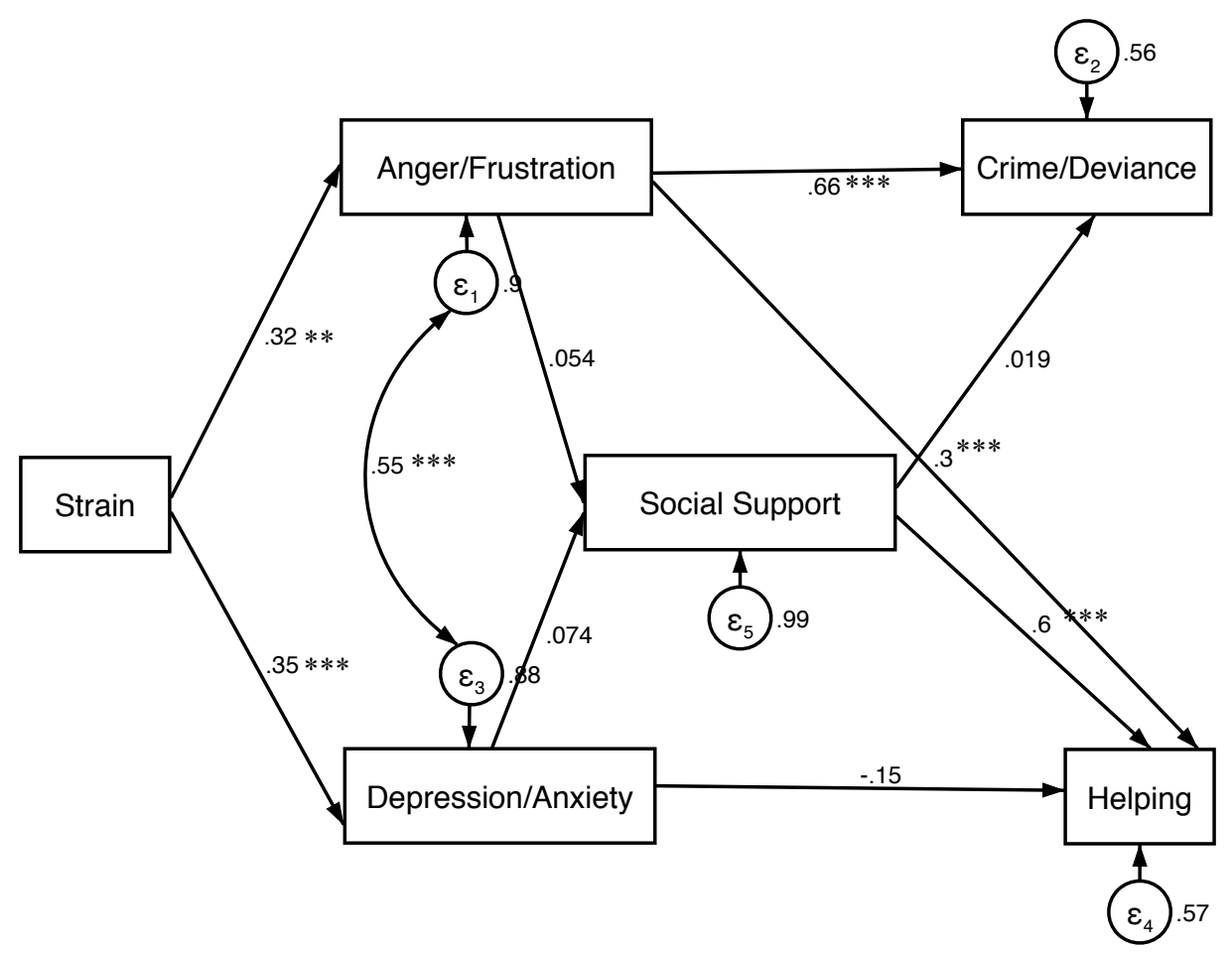

Notes: ${ }^{*} p<0.05 ;{ }^{* *} p<0.01 ;{ }^{* *} p<0.001$ (two-tailed tests)

Academic Strain Mediator by Gender. Due to the amount of literature discussing gender differences in how individuals respond to strain, analyses were run for males and females separately using the academic strain model, as that model had the best fit. It was theorized that academic strain would be more likely to activate the negative emotions of anger/frustration in males, which would be mediated by social support and result in deviant behaviors. Results from 
this model do not show support for the relationship between strain and those negative emotions in males. As academic strain increases, the negative emotions of anger/frustration do not appear to increase significantly $(-0.01, p=0.94)$. Also, social support does not significantly mediate the relationship between anger/frustration and crime/deviance $(0.09, p=0.62)$. Instead, increases in anger and frustration do lead to an increase in crime/deviance $(0.43, p=0.03)$.

Interestingly, males tend to experience depression/anxiety as a result of academic strain, which was not predicted based on previous literature. The experience of depression/anxiety should lead to helping behavior, which is mediated by social support. For males, as academic strain increases, the negative emotions of depression/anxiety significantly increase $(0.49, p=$ 0.004). Social support does significantly mediate the relationship between depression/anxiety and helping behavior $(0.46, p=0.002)$. Also, increases in depression and anxiety lead to a significant increase in helping behavior $(0.30, p=0.03)$. This finding is interesting in that it is not a male stereotypical emotion or behavioral response.

These findings support the relationship from strain to crime but contradict findings in previous studies that report that males are more likely to experience anger/frustration than depression/anxiety (Broidy and Agnew 1997; Posick, Farrell, and Swatt 2013). However, they also support the relationship from strain to helping. While social support does not impact the relationship between anger/frustration and crime/deviance, it does improve the relationship between depression/anxiety and helping behavior.

The fit statistics for this path model are also excellent. The model $\chi^{2}$ is not significant $(5.33, p=0.502)$. Both the RMSEA and SRMR fall below the 0.08 cutoff criteria ( 0.00 and 0.07 , respectively) while the CFI value is above the recommended $0.90-0.95$ cutoff value (1.00). A check of modification indices recommends no further changes to the paths in the model. 


\section{Figure 14. Academic Strain Mediated Path Model for Males}

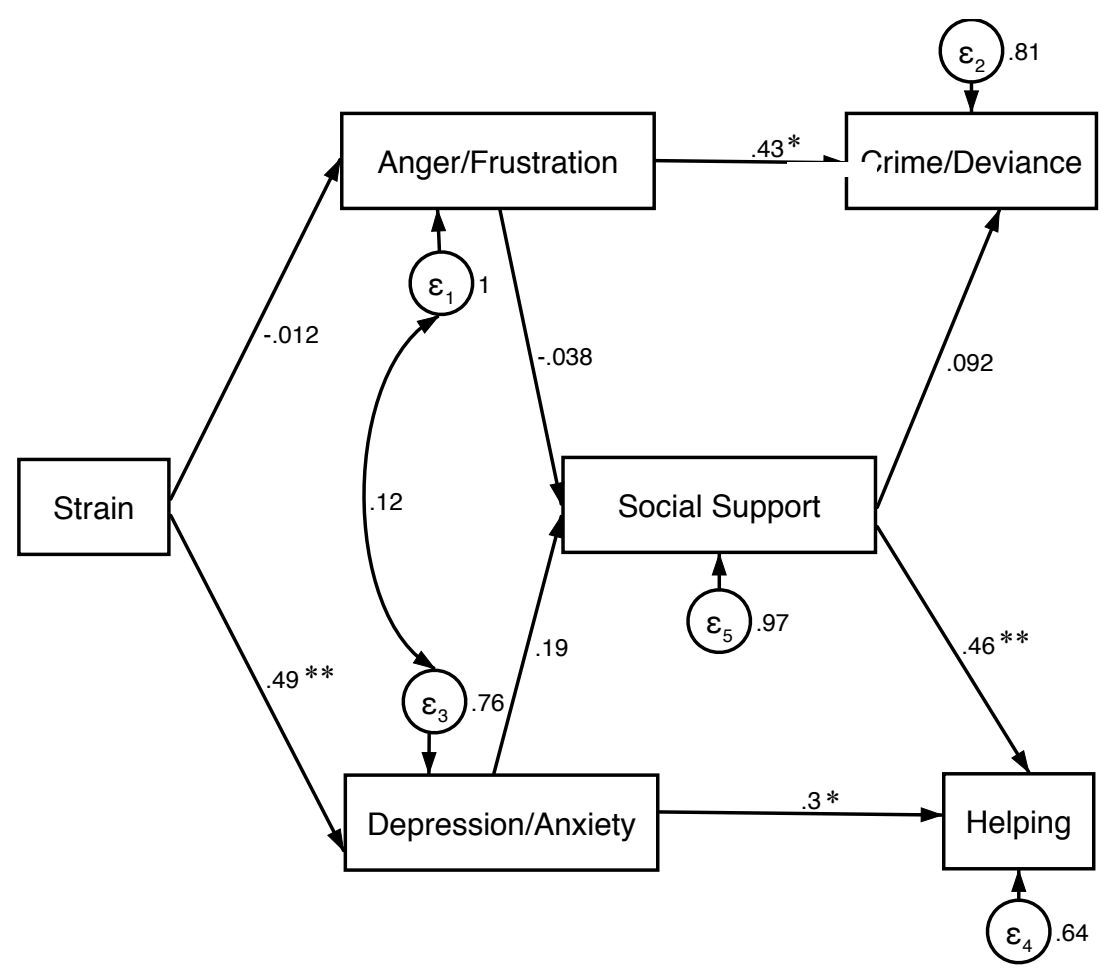

Notes: ${ }^{*} p<0.05 ; * * p<0.01 ; * * * p<0.001$ (two-tailed tests)

It was theorized that academic strain would be more likely to activate the negative emotions of depression and anxiety in females, which would be mediated by social support and result in helping behaviors. Females do experience depression/anxiety as a result of academic strain, supporting previous literature. The experience of depression/anxiety should lead to helping behaviors, which are mediated by social support. For females, as academic strain increases, the negative emotions of depression/anxiety increase significantly $(0.36, p<0.01)$. Social support does not significantly mediate the relationship between depression/anxiety and helping behavior $(0.10, p=0.38)$. Also, increases in depression and anxiety do not lead to an increase in helping behavior from females $(0.05, p=0.67)$.

Contrary to what previous literature states, women also experience anger and frustration as the result of academic strain. As academic strain increases, the negative emotions of 
anger/frustration appear to increase significantly $(0.46, p<0.001)$. However, social support does not significantly mediate the relationship between anger/frustration and crime/deviance for females $(-004, p$ 0.54). Instead, increases in anger and frustration do lead to an increase in crime/deviance $(0.33, p=0.04)$.

The fit statistics for this path model are also excellent. The model $\chi^{2}$ is not significant (5.27, $p=0.509)$. Both the RMSEA and SRMR fall below the 0.08 cutoff criteria $(0.00$ and 0.05 , respectively) while the CFI value is above the recommended $0.90-0.95$ cutoff value (1.00). A check of modification indices recommends no further changes to the paths in the model.

\section{Figure 15. Academic Strain Mediated Path Model for Females}

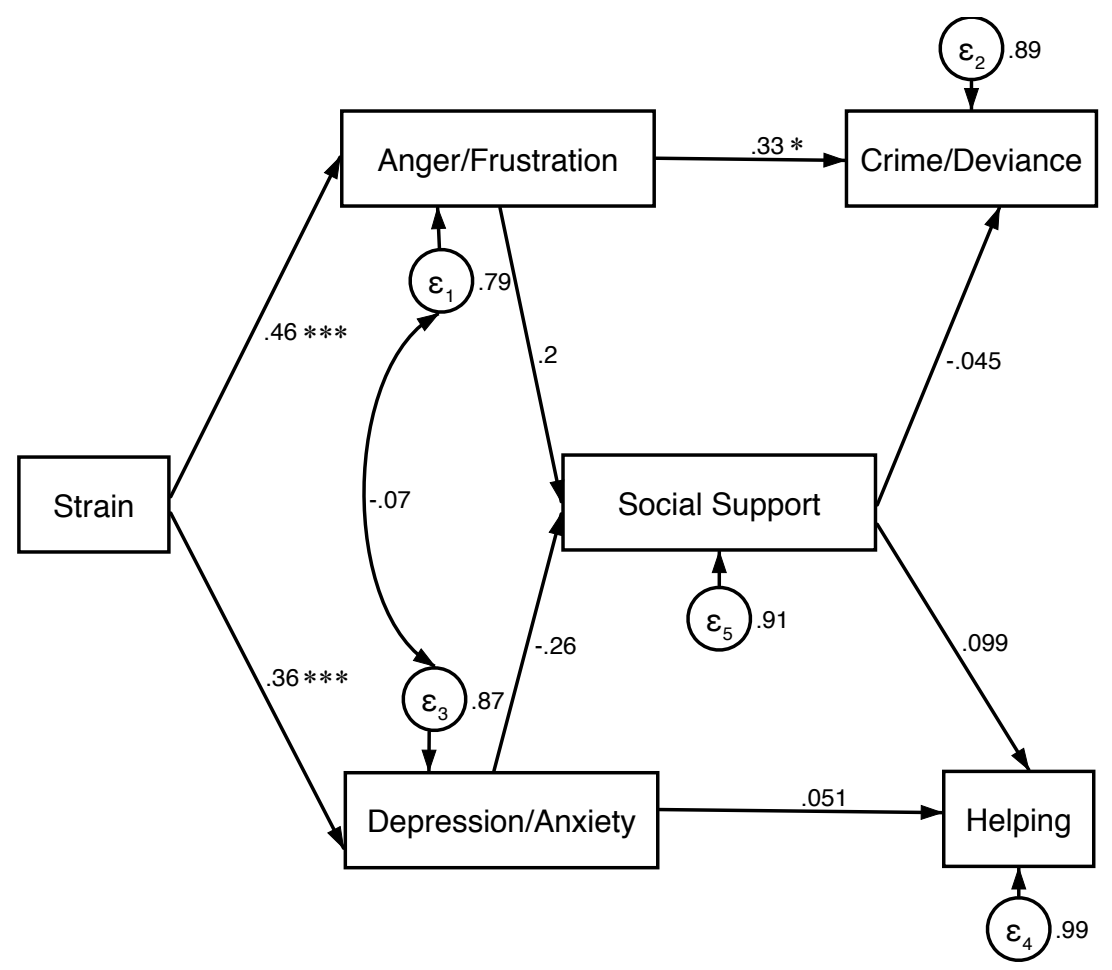

Notes: ${ }^{*} p<0.05 ; * * p<0.01 ; * * * p<0.001$ (two-tailed tests) 


\section{DISCUSSION}

This research set out to empirically evaluate an extension of Agnew's General Strain Theory (1992). GST postulates that negative external stressors will lead to some negative emotion (typically anger/frustration), which will result in criminal coping or deviance. I extended that theory to include the negative emotions of anxiety and depression to determine if external stressors could result in helping behaviors rather than criminal coping. Specifically, by incorporating the literature on feel bad, do good I was able to provide a connection between individuals feeling bad from a strainful experience and therefore seeking to do good in order to reduce those negative feelings or repair self image. I also paid attention to the role that social support had in the relationship between negative emotions experienced after a stressful experience and the way individuals reacted. Data was collected on four different external stressors: academic, interpersonal, financial, and victimization. The results of this study suggest that different strains lead to different emotional and therefore physical reactions to strain. Additionally, males and females have different emotional and behavioral reactions to strain, specifically academic stressors. Furthermore, the results raise questions about the nature of social support as either a moderating or mediating coping mechanism in response to strain.

The path analyses regarding moderation and mediation indicated some very different relationships for Agnew's (1992) GST. While all of the moderation path models indicated increases in anger and frustration after experiencing strain, not all of them led to criminal behaviors while all of the mediation paths did. Also, none of the mediation paths indicated a significant effect of social support on criminal behaviors, whereas the victimization moderation model indicated that increases in social support actually led to increases in deviant behaviors, whereas it should have led to decreases. The financial and interpersonal mediation models also 
indicated that anger and frustration could led to helping behaviors. The moderation path models of these same strains did not indicate any such relationship, however financial strain did indicate increases in helping behavior in the presence of social support.

In the moderator models, strain led to anger and frustration for all four of the strain types. However, anger and frustration only led to criminal behaviors in the financial strain model. In that same model, it appeared as though increases in depression and anxiety led to decreases in helping, which goes against the theoretical model. Perhaps individuals who were anxious or depressed about their financial situation turned more inwards and were motivated to focus on their own problems than to focus on those of others. Due to the moderating effects of social support, however, as social support increased it negated the negative effects of depression and anxiety and actually led to increases in helping behavior. Therefore, if the individual had access to social support, perhaps they had access to significant others who could help them with their own financial crisis, and thus motivate them to do the same and help others (Cohen and Wills 1985).

In the victimization model, it appeared as though individuals who received social support experienced increases in deviant behaviors, even though they were already inclined to behave criminally after experiencing anger and frustration. This relationship is surprising, considering social support is supposed to lead to decreases in criminal behaviors. However, one explanation for this relationship may be that the strained individual sought social support from deviant others, and therefore was more likely to behave criminally.

While academic and interpersonal strain led to increases in negative emotions, neither of the models saw increases in either helping or criminal behaviors. It may be that individuals in these situations saw them as stressful but did not feel the need to outwardly react. Failing a class 
may cause the respondent to feel strain, however there are ways to work around that, such as changing one's major or retaking the class that does not involve the need to exert one's energy elsewhere. Also, in regards to the interpersonal strain scenario, the respondent may have been stressed because they were left stranded at the last minute, but these things happen and they can always reschedule their appointment. Their negative emotions are most likely directed towards the individual who spurned them and not towards affecting others.

Similar to the results from the moderating tests of the Strain Theory Model of Criminal and Prosocial behavior, analyses with social support as a mediator also found that all of the strainful scenarios led to anger and frustration. However, and in greater support of Agnew's initial theory (1992), there were also significant increases in criminal coping and deviance in response to these negative emotions. Interpersonal strain was the most likely to lead to an increase in anger and frustration when strain increased, while academic strain had the lowest coefficient for anger and frustration to result in deviance. Strain leads to crime if it comes in the form of working in a secondary labor market or experiencing prejudice and discrimination or even having abusive peer relations (Agnew 2001). This may explain why victimization and financial strain both resulted in anger and frustration, and thus resulted in crime and deviance. Baron (2004) found that theft should not lead to anger, but that violent victimization does. Perhaps the victimization scenario was just threatening enough that the respondents perceived the situation as anger inducing.

The interpersonal strain mediation model had the highest coefficient for strain leading to anger and frustration (0.38), and the highest coefficient for anger and frustration to lead to deviance (0.67). Perhaps the reason for this springs from the fact that the individual is being harmed by someone close to them, causing a stronger emotional reaction than the other stressors, 
and thus resulting in stronger emotions such as anger and frustration. As their anger increases, their inhibition decreases, therefore resulting in more deviant behaviors (Sigfusdottir, Farkas, and Silver 2004).

This research provides support not only for Agnew's GST (1992) linking negative emotions to crime and deviance, but also the addition of depression and anxiety and the potential for those negative emotions to lead to helping. Of the four mediation models, only victimization strain did not lead to increases in anxiety and depression. Similarly, the victimization strain scenario was the only moderated path model that did not create significant feelings of depression and anxiety. Academic strain had the largest impact on anxiety and depression, followed by financial, and finally interpersonal strain. The academic strain model was the only one to indicate that depression and anxiety led to helping behavior. The initial model for interpersonal strain indicated that depression and anxiety led to helping, however once the path was created from anger and frustration to helping, the significance disappeared.

In regards to academic strain, it could be that failure and low grades really are perceived as distressful rather than stressful, which may be why that scenario was more likely to lead to depression and anxiety and in turn helping behaviors rather than criminal coping (Mathew et al. 2015). Stressful situations create non-specific responses to taxing demands, whereas distressful situations are troubling or confusing but not necessarily as demanding as stressful scenarios (Levi 1972). Therefore distressed individuals' responses to strain are not as strongly emotionally driven as more stressed individual responses.

For interpersonal strain, family conflict is equally likely to result in anger and depression (Sigfusdottir, Farkas, and Silver 2004). Due to the nature of the scenario, the respondent could have even experienced resentment, because they were cancelled on at the last minute. Bao, Haas, 
and Pi (2004) state that resentment, just like depression, was more likely to result in nondelinquent responses than if individuals experienced anger. Interestingly, the path model indicates the opposite. Individuals who have experienced interpersonal strain may not perceive their negative moods of depression and anxiety to be alterable, and therefore avoid considering helping others because it would not improve their negative emotions (Manucia, Baumann, Cialdini 1984).

The literature on victimization strain primarily indicates that anger is the most common emotional response to that particular stressor, with minimal support for the relationship between the strain and depression and anxiety (Baron 2004; Moon, Blurton, and McCluskey 2008). Individuals who have been victimized might not perceive helping to be the best way to improve their mood, and therefore might not help (Schaller and Cialdini 1988). Regardless of the emotions felt after experiencing financial strain, the common theme is for individuals to respond criminally or delinquently, which may explain why respondents in this scenario were more likely to behave criminally than to participate in helping behavior (Baron 2007; Moon, Blurton, and McCluskey 2008). Individuals experiencing anxiety and depression as a result of financial strain potentially see helping others as a costly addition to everything else they are doing and may thus reject participating in helping behaviors (Schaller and Cialdini 1998).

Interestingly, anger and frustration also led to helping in two of the models (interpersonal and financial). The current literature on feel bad, do good states that anger and grief are the only exceptions to the phenomenon. It appears as though there may be an exception to that exception. This finding may be supported by research by Doorn, Zeelenberg, and Breugelmans (2014), who state that anger is seen as too one-sided and should be seen as a more dynamic emotion. Frijda (1988) explains, "Emotions arise in response to events that are important to the individual's 
goals, motives, or concerns. Every emotion hides a concern, that is, a more or less enduring disposition to prefer particular states of the world. A concern is what gives a particular event its emotional meaning" (p. 351). Typically, the purpose of anger is to get even for unjust or unfair experiences. However, when individuals perceive that someone is at an unfair disadvantage or amongst the ones harmed, they are inclined to experience anger that is directed either towards prosocial behaviors or punishing the perpetrator (Doorn, Zeelenberg, and Breugelmans 2014). This may be why individuals experiencing financial strain or interpersonal strain experienced anger/frustration that resulted in helping behaviors - they saw themselves as disadvantaged/harmed by the situation and in turn wanted to help others who were in similar positions. To determine the validity of that statement, future research could examine the specific kind of helping they would engage in to validate this result as this current study has any kind of helping combined. Individuals experiencing interpersonal strain may be experiencing negative emotions that are solely directed towards their transgressor, which may be why they are still willing to help others. Future studies could more closely examine who or what the negative emotions are displaced towards and who the helping behaviors are directed to in order to determine that relationship. Financial stressors leading to anger and frustration may motivate the individual to help others to improve their self-esteem and self-image, since their efforts to achieve the American Dream have apparently not been successful (Isen, Horn, and Rosenhan 1973). Future studies could measure the desirability of financial achievement to determine how motivating this factor may be to certain individuals.

The results for the role of social support both GST and the Strain Theory Model of Criminal and Prosocial Behavior were mixed. In the mediated path models, it did little to significantly mediate the relationships between the negative emotions resulting from strain and 
the response to the stressful situation. When it did play a role in the financial and men's academic moderating models, it actually led to increases in deviant behavior. While it was expected that social support would decrease the likelihood of deviant responses, perhaps individuals who were strained sought deviant others to help them find an outlet and reduce their negative feelings. Social support actually negated the negative emotions of depression and anxiety in the victimization moderating model. Here it appears as though the strained individuals overcame their negative emotions through the support of their friends and used that support to direct them towards prosocial behaviors. Social support did significantly mediate the relationship between depression/anxiety and helping in all of the mediating models. However, that mediation did not improve the likelihood of individuals participating in helping behaviors in any of the models except for academic strain. Individuals in the academic setting may rely on peer support and social comparison to determine how they respond to receiving a poor grade. It may be beneficial to conduct a study that examines the amount of social comparison an individual participates in to see if there is a correlation between that and the influence of social support. When social support was significant for helping, it increased helping in the financial moderating model, whereas in the mediating models, it was significant for all of the models but only increased the likelihood of helping behaviors in the academic model. It appears as though for moderating it just matters whether or not the individual has access to social support, whereas for the mediating models, it matters if the individual has access to, and actually utilizes their social support. The scale used to measure social support was chosen for it's reference to individuals seeking help in stressful situations, but how it was measured in this study may not have been exactly how Agnew conceived it to work in his GST. While the social support scale does ask the respondent about the availability of their social support, it does not ask about 
whether or not they actually access that support structure when they are stressed. It would be beneficial to conduct a study that includes both.

The differences in response to strain by gender were also rather surprising. Their responses were atypical not only concerning gender stereotypes, but also considering previous strain research. Males experienced increases in depression and anxiety as a response to strain, as well as increases in helping in the case of the mediated models. Social support also mediated the relationship between depression/anxiety and helping for males. Both the emotional and behavioral response to strain were atypical for men. Most of the previous literature indicated that males would experience anger and frustration, and in turn criminally cope, but the results of this study indicate the exact opposite (Broidy and Agnew 1997; Jang 2007). While the moderated model of academic strain for males indicated increases in depression and anxiety for males, those increases were not moderated by social support, and did not lead to increases in helping behavior. Again, their emotional response was atypical, but was not followed up by an atypical behavioral response. Also interesting was the fact that social support led to increases in criminal behaviors by males when it moderated the negative emotional affect and behavioral response. It appears as though males have access to peers that enable their deviant behaviors, rather than prevent them from occurring.

Females indicated the exact opposite of their male counterparts. They indicated an increase in anger and frustration after reading the stressful academic scenario and incidentally indicated an increase in deviant behavior in the mediated model. Based on this finding, females appear to fit the "overly emotional" stereotype, but in turn behave non-stereotypically by participating in criminal behavior rather than helping. Unlike males, females are more likely to turn to social support in response to their experience of negative emotions in the mediated 
models, but that does not affect their response to the strain. The moderated models indicated that while females were not inclined to physically respond to strain in one way or another, they were likely to experience both negative emotion sets, keeping in line with the "overly emotional" results found in the mediated models. These differences are interesting, but Lowe and May's (2011) research indicated that in high school students, males and females reacted to strain equally, so that may explain why these differences exist. The females may have lashed out in deviance due to pressures to perform well in school because they see it as the only pathway to economic success/stability and they do not want to let their family/peers down. The male respondents may have turned to helping because they were humbled by their failure or maybe they perceive themselves as having a strong peer network at school that motivates them to behave prosocially. These differences most likely would not be seen in the other three scenarios. Broidy and Agnew (1997) indicated that males were more likely to experience financial strain, victimization, and interpersonal conflict, and their research indicated that males were more likely to experience anger when exposed to these stressors.

\section{Limitations}

Despite these conclusions, this study is not without its limitations. First, the study uses vignette surveys. Due to the fact that the scenarios are hypothetical, it is hard to determine if the responses indicated reflect exactly how the respondent would react in that same situation. When it comes to responses to situations, individuals typically have a script that they follow and their responses then become habitual. Those actions are usually taken with a particular goal in mind, and given that GST reactions are typically oriented towards some type of goal, individual reactions are most likely planned (Ajzen 1985). Individuals who believed they would help may not actually do so in reality. However, these individuals are more inclined to help in real-life than 
respondents who did not indicate participating in helping behaviors (Collins 2012). Additionally, the fact that the respondents took the survey and answered the questions about their perceived and actual behaviors increases their likelihood of participating in those behaviors in the future (Beck 1991).

Second, the survey has the prompt "how would you respond to any stressful situation" when it should have actually stated "how would you respond to this stressful situation." Therefore, it is hard to determine if the respondents kept the initial prompt in mind when responding or if they were thinking of any stressful experience that they have had within the past 12 months. Also, other researchers' scales were used for the measures of strain, anger/frustration, depression/anxiety, and social support. Due to the nature of these scales, the measures were very general and had they been altered and tailored to the specific scenarios the subjects read, stronger results may have been obtained.

Third, as previous literature has not broken apart anxiety and depression, this research has not either. It is highly possible that if broken into two separate entities, the results could potentially be different considering some research that suggests these emotions are entirely different in their experience and expression (Dobson 1985; Rappaport, Moskowitz, and D’Antono 2014).

Fourth, the current study only focused on prosocial or "other motivated" forms of helping, and did not consider other "positive" or "self-helping" types of help that are not necessarily social but still good in nature (i.e. exercising, cleaning, etc.). It is possible for individuals experiencing strain to be motivated to participate in these inward forms of helping regardless of negative affect experienced, similar to the models seen with interpersonal and 
financial strain. Individuals experiencing anger and frustration might engage in exercise to help blow off steam and therefore participate in helping behaviors.

Additionally, the Strain Model of Criminal and Prosocial Behaviors does not take into account the opportunities individuals have to behave in a specific manner. Someone may be motivated to help due to strainful experiences, however if they do not have available opportunities or methods for finding something or someone to help, then they may not actually behave prosocially. For instance, students might be more likely to indicate that they will help as well as actually help because universities now have multitudes of opportunities for people to engage in prosocial behaviors. On the other hand, Mechanical Turk respondents might not have access to nearly as many of those opportunities, therefore decreasing their likelihood of indicating that they would help, as well as their actual participation in helping behaviors.

Finally, although the survey contained controls for actual experiences and social value orientation, the current study did not include those measures in the analyses due to time and space constraints. Including an individual's actual experience and response to stressful situations should correlate with their expected responses and provide more support for how an individual would actually respond in the proposed stressful situation. It should strengthen the argument for how individuals would actually behave even though they are responding to a hypothetical scenario. The slider bar activity for SVO should indicate relationships between those who indicate willingness to help and who also reveal prosocial tendencies in the activity. Perhaps by separating respondents out by altruistic, prosocial, individualistic, or competitive, results may indicate that helping behaviors may be more likely for one type of individual versus another, regardless of stressful situation posed. 


\section{Conclusion}

At a minimum, I find support for the theoretical model stating that strain can lead to more than just crime and deviance in both the moderated and the mediated models. Strain can in fact lead to both anger/frustration and depression/anxiety. Also, helping can result from not only depression and anxiety, but also anger and frustration as shown in the mediated models, which was not predicted but would be a fruitful line of future research. Since this analysis is a limited test of a larger theoretical framework, it can only tentatively be concluded that strain indeed leads to helping behaviors in certain stressful situations. Unfortunately, social support does not appear to play a key role in the relationship between negative emotion experienced and perceived reaction, especially in the moderated models. Social support only played a significant role in three of the moderation models, and actually increased criminal deviance in two of them. On the other hand, social support only improved the likelihood of helping in one of the mediated models.

The ideas tested in this study show how various external stressors can lead to varying negative emotions, which can lead to different expressions of those negative emotions. Research into other types of specific stressful situations within those four veins of strain could potentially lead to more support for this theoretical structure of GST, particularly because emotional responses are context specific. More research should also be directed towards the dynamic nature of emotions, because it appears as though helping can be the result of more than just one type of emotion. 


\section{REFERENCES}

Acock, Alan C. 2013 Discovering Structural Equation Modeling Using Stata. College Station, TX: Stata Press.

Agnew, Robert. 1992. "Foundations for a General Strain Theory of Crime and Delinquency." Criminology 30(1): 47-87.

Agnew, Robert. 2001. "Building on the Foundation of General Strain Theory: Specifying the Types of Strain Most Likely to Lead to Crime and Delinquency." Journal of Research in Crime and Delinquency 38(4): 318-361.

Agnew, Robert. 2008. Strain Theories. In V. Parrillo (Ed.) Encyclopedia of social problems. (pp. 904-906) Thousand Oaks: SAGE Publications, Inc.

Agnew, Robert and Timothy Brezina. 1997. "Relational Problems with Peers, Gender, and Delinquency." Youth and Society 29(1): 84-111.

Agnew, Robert and Helene Raskin White. 1992. "An Empirical Test of General Strain Theory." Criminology 30(4): 475-499.

Ajzen, Icek. 1985. "From Intentions to Actions: A Theory of Planned Behavior.” Action Control p. 11-39. Springer Berling Heidelberg .

Antonaccio, Olena, William R. Smith, and Feodor A. Gostjev. 2015. “Anomic Strain and External Constraints: A Reassessment of Merton's Anomie/Strain Theory Using Data from Ukraine." International Journal of Offender Therapy and Comparative Criminology 59(10): 1079-1103

Aseltine, Robert H., Susan Gore, and Jennifer Gordon. 2000. "Life Stress, Anger and Anxiety, and Delinquency: An Empirical Test of General Strain Theory." Journal of Health and Social Behavior 41(3): 256-275. 
Asgari, Shaki. 2016. "The Influence of Varied Levels of Received Stress and Support on Negative Emotions and Support Perceptions." Current Psychology 35(3): 386-396.

Aslund, Cecilia, Peter Larm, Bengt Starrin, and Kent W. Nilsson. 2014. "The Buffering Effect of Tangible Social Support on Financial Stress: Influence on Psychological Well-Being and Psychosomatic Symptoms in a Large Sample of the Adult General Population.” International Journal for Equity in Health 13: 85.

Bao, Wan-Ning, Ain Haas, and Yijun Pi. 2004. "Life Strain, Negative Emotions, and Delinquency: An Empirical Test of General Strain Theory in the People's Republic of China." International Journal of Offender Therapy and Comparative Criminology 48(3): 281-297.

Baron, Stephen W. 2004. “General Strain, Street Youth and Crime: A Test of Agnew's Revised Theory." Criminology 42(2): 457-484.

Baron, Stephen W. 2007. "Street Youth, Gender, Financial Strain, and Crime: Exploring Broidy and Agnew's Extension to General Strain Theory.” Deviant Behavior 28: 273-302.

Batson, C. Daniel. 1987. "Prosocial Motivation: Is it Ever Truly Altruistic?" Advances in Experimental Social Psychology 20: 65-122.

Batson, C. Daniel, Judy G. Batson, Cari A. Griffitt, Sergio Barrientos, J. Randall Brandt, Peter Sprengelmeyer, and Michael J. Bayly. 1989. "Negative-State Relief and the EmpathyAltruism Hypothesis." Journal of Personality and Social Psychology 56(6): 922-933.

Beck, Lisa. 1991. "Predicting Dishonest Actions Using the Theory of Planned Behavior." Journal of Research in Personality 25(11):285-301.

Botchkovar, Ekaterina and Lisa Broidy. 2013. "Accumulated Strain, Negative Emotions, and 
Crime: A Test of General Strain Theory in Russia." Crime \& Delinquency 59(6): 837860.

Broidy, Lisa M. 2001. “A Test of General Strain Theory.” Criminology 39(1): 9-36.

Broidy, Lisa and Robert Agnew. 1997. "Gender and Crime: A General Strain Theory Perspective." Journal of Research in Crime and Delinquency 34(3): 275-306.

Cialdini, Robert B. and Douglas T. Kenrick. 1976. "Altruism as Hedonism: A Social Development Perspective on the Relationship of Negative Mood State and Helping.” Journal of Personality and Social Psychology 34(5): 907-914.

Cialdini, Robert B., Mark Schaller, Donald Houlihan, Kevin Arps, Jim Fultz and Arthur L. Beaman. 1987. "Empathy-Based Helping: Is It Selflessly or Selfishly Motivated?" Journal of Personality and Social Psychology 52(4): 749-758.

Cohen, Albert K. 1965. "The Sociology of the Deviant Act: Anomie Theory and Beyond." American Sociological Review 30: 5-14.

Cohen, Albert K. 1997. “An Elaboration of Anomie Theory.” Pp. 52-61 in The Future of Anomie Theory, edited by Nikos Passas, Robert Agnew and Robert K. Merton. Boston: Northeastern University Press.

Cohen, Sheldon and Thomas Ashby Wills. 1985. "Stress, Social Support, and the Buffering Hypothesis." Psychological Bulletin 98(2): 310-357.

Collins, Randall. 2013. "Entering and Leaving the Tunnel of Violence: Micro-Sociological Dynamics of Emotional Entrainment in Violent Interactions." Current Sociology 61(2):132-51.

Consiglio, Chiara. 2014. "Interpersonal Strain at Work: A New Burnout Facet Relevant for the Health of Hospital Staff." Burnout Research 1(2): 69-75. 
Delamater, John D., Daniel J. Myers, and Jessica L. Collett. 2015. Social Psychology. $8^{\text {th }}$ ed. Boulder, Colorado: Westview Press.

Ding, Wan, Ruibo Xie, Binghai Sun, Weijian Li, Duo Wang, and Rui Zhen. 2016. "Why Does the 'Sinner' Act Prosocially? The Mediating Role of Guilt and the Moderating Role of Moral Identity in Motivating Moral Cleansing.” Frontiers in Psychology 7: 1-8.

Dobson, Keith S. 1985. “The Relationship Between Anxiety and Depression.” Clinical Psychology Review 5(4): 307-324.

Doorn, Janne van, Marcel Zeelenberg, and Seger M. Breugelmans. 2014. “Anger and Prosocial Behavior.” Emotion Review 6(3): 261-268.

Forest, Duncan, Margaret S. Clark, Judson Mills, and Alice M. Isen. 1979. "Helping as a Function of Feeling State and Nature of the Helping Behavior." Motivation and Emotion 3(2): 161-169.

Frijda, Nico H. 1988. “The Laws of Emotion.” American Psychologist 43(5): 349-358.

Gollwitzer, Mario and Brad J. Bushman. 2011. "Do Victims of Injustice Punish to Improve Their Mood?" Social Psychology and Personality Science 00(0): 1-9.

Isen, Alice M., Nancy Horn, and D. L. Rosenhan. 1973. "Effects of Success and Failure on Children's Generosity." Journal of Personality and Social Psychology 27(2): 239-247.

Jang, Sung Joon. 2007. “Gender Differences in Strain, Negative Emotions, and Coping Behaviors: A General Strain Theory Approach.” Justice Quarterly 24(3): 523-553.

Jang, Sung Joon and Byron R. Johnson. 2003. "Strain, Negative Emotions, and Deviant Coping Among African Americans: A Test of General Strain Theory." Journal of Quantitative Criminology 19(1): 79-105.

Jang, Sung Joon and Juyoung Song. 2015. “A 'Rough Test' of a Delinquent Coping Process 
Model of General Strain Theory." Journal of Criminal Justice 43(6): 419-430.

Jun, Sangmin and Eunsil Choi. 2015. “ Academic Stress and Internet Addiction from General Strain Theory Framework." Computers in Human Behavior 49: 282-287.

Lee, Daniel R. and Jeffrey W. Cohen. 2008. "Examining Strain in a School Context." Youth Violence and Juvenile Justice 6(2): 115-135.

Levi, Lennart. 1972. Stress and Distress in Response to Psychosocial Stimuli: Laboratory \& Real Life Studies on Sympatho-adrenomedullary \& Related Reactions. Pergamon Press Ltd., Headington Hill Hall, Oxford.

Lin, Wen-Hsu and Chin-Chun Yi. 2016. "Family and School Strains and Their Effects on Adolescent Deviance in Taiwan: A Mediating Study." Youth and Society 48(4): 496-520.

Lowe, Nathan C. and David C. May. 2011. "Responses to Scenarios That May Provoke Acts of Conflict and Aggression among the General Public: An Exploratory Study.” Journal of Interpersonal Violence 26(8): 1606-1627.

Manucia, Gloria K., Donald J. Baumann, and Robert B. Cialdini. 1984. "Mood Influences on Helping: Direct Effects or Side Effect?” Journal of Personality and Social Psychology 46(2): 357-364.

Mathew, Naina, Deepika Cecil Khakha, Ashia Qureshi, Rajesh Sagar, and Cecil Christopher Khakha. 2015. "Stress and Coping among Adolescents in Selected Schools in the Capital City of India.” Indian J Pediatr 82(9): 809-816.

Merton, Robert K. 1938. "Social Structure and Anomie.” American Sociological Review 3(5): 672-682.

Moon, Byongook, David Blurton, and John. D. McCluskey. 2008. “General Strain Theory and 
Delinquency - Focusing on the Influences of Key Strain Characteristics of Delinquency.” Crime and Delinquency 54(4): 582-613.

Murphy, Ryan O., Kurt A. Ackermann, and Michael J. J. Handgraaf. 2011. "Measuring Social Value Orientation.” Judgment and Decision Making 6(8): 771-781,

Myers, D. G., \& Twenge, J. M. 2013. Social psychology. $11^{\text {th }}$ ed. New York: McGrawHill.

Nickell, G. 1998. "The Helping Attitudes Scale.” Paper presented at 106th Annual Convention of the American Psychological Association at San Francisco, August, 1998.

Ping, R.A. (2009). "Estimating endogenous interactions." [on-line paper]. http://www.wright.edu/ robert.ping/ Endog_ints2.doc.

Piquero, Nicole Leeper and Miriam D. Sealock. 2004. "Gender and General Strain Theory: A Preliminary Test of Broidy and Agnew's Gender/GST Hypotheses." Justice Quarterly 21(1): $125-158$.

Pooja, Abeeda A., Dirk De Clercq, and Imanol Belausteguigoitia. 2016. “Job Stressors and Organizational Citizenship Behavior: The Roles of Organizational Commitment and Social Interaction." Human Resource Development Quarterly 27(3): 373-405.

Rappaport, Lance M., D. S. Moskowitz, and Bianca D’Antono. 2014. "Naturalistic Interpersonal Behavior Patterns Differentiate Depression and Anxiety Symptoms in the Community." Journal of Counseling Psychology 61(2): 253-263.

Rebellon, Cesar J., Michelle E. Manasse, Robert Agnew, Karen T. Van Gundy, and Ellen S. Cohn. 2016. "The Relationships between Gender and Delinquency: Assessing the Mediating Role of Anticipated Guilt.” Journal of Criminal Justice 44: 77-88.

Robbers, Monica L. P. 2004. "Revisiting the Moderating Effect of Social Support on Strain: A 
Gendered Test.” Sociological Inquiry 74(4): 546-569.

Roberts, William, Janet Strayer, and Susanne Denham. 2014. "Empathy, Anger, and Guilt: Emotions and Prosocial Behavior." Canadian Journal of Behavioral Science 46(4): 465474.

Roos, Sanna, Ernest V. E. Hodges, and Christina Salmivalli. 2014. "Do Guilt- and ShameProneness Differentially Predict Prosocial, Aggressive, and Withdrawn Behaviors During Early Adolscence?” Developmental Psychology 50(3): 941-946.

Rushtown, J. Philippe, Roland D. Chrisjohn, and G. Cynthia Fekken. 1981. "The Altruistic Personality and the Self-Report Altruism Scale." Personality and Individual Differences 2: $293-302$.

Saarni, C. 1997. “Coping with Aversive Feelings.” Motivation and Emotion 21(1): 45-63.

Sarason, Irwin G., Barbara R. Sarason, Edward N. Shearin, and Gregory R. Pierce. 1987. “A Brief Measure of Social Support: Practical and Theoretical Implications.” Journal of Social and Personal Relationships 4: 497-510

Schaller, Mark and Robert B. Cialdini. 1988. "The Economics of Empathic Helping: Support for a Mood Management Motive." Journal of Experimental Social Psychology 24(2): 163181.

Sigfusdottir, Inga-Dora, George Farkas, and Eric Silver. 2004. "The Role of Depressed Mood and Anger in the Relationship Between Family Conflict and Delinquent Behavior.” Journal of Youth and Adolescents 33(6): 509-522.

Son, Joonmo and John Wilson. 2015. “The Psycho-Social Processes Linking Income and Volunteering: Chronic Financial Strain and Well-Being." Sociological Forum 30(4): 1059-1081. 
Staff, Jeremy and Christopher Ugen. 2003. "The Fruits of Good Work: Early Work Experiences and Adolescent Deviance." Journal of Research in Crime and Deliquency 40(3): 263290.

Tedor, Miyuki Fukushima, Susan F. Sharp, and Emiko Kobayashi. 2015. "A Cross-Cultural Examination of the Disjuncture Between Aspirations and Expectations/Perceived Outcomes: Strain and Academic Deviance in the United States and Japan.” Sociological Inquiry 85(3): 462-491.

Wilhelm, Mark O. and René Bekkers. 2006. "Helping Behavior, Dispositional Empathic Concern, and the Principle of Care." Social Psychology Quarterly 73(1): 11-32.

Williams, Trish, Jennifer Connolly, Debra Pepler, and Wendy Craig. 2005. "Peer Victimization, Social Support, and Psychological Adjustment of Sexual Minority Adolescents.” Journal of Youth and Adolescence 34(5): 471-482.

Zhang, Jie and Juncheng Lyu. 2014. "Reliability, Validity, and Preliminary Hypothesis Tests for the English Version of the Psychological Strain Scales." Journal of Affective Disorders 164: 69-75. 


\section{APPENDIX A - Strain Scenarios}

Imagine yourself in the following scenario:

\section{Interpersonal}

You are experiencing conflict with one of your close friends, colleagues, or family. You had trusted your friend/colleague/family member to take you to the doctor for an appointment. You find out a half hour before the appointment that they can no longer get you. Unfortunately, you need to go to this appointment or else you will get charged a fee, and will not be able to schedule another appointment for months. You end up not making it to your appointment. Later you find out that they had been on a date instead of taking you to your appointment. Based on this information, answer the following questions.

\section{Financial}

You are unable to pay your rent for the upcoming month. Rent is due in three days and your paycheck does not come for another week. Even if you do get paid, you are still going to be just shy of your rent by $\$ 50$. Your pay rate is fixed and you have no chance of earning the money in time. Based on this information, answer the following questions.

\section{Victimization}

You are walking down the street after dinner with your friends. Your turn off to head to the lot your car is in and find yourself walking alone in the dark. You are approached by a stranger who grabs your arms and tells you that if you do not give him your money, he will hurt you. Based on this information, answer the following questions.

\section{Academic}

You are currently in a class that is a requirement for you to graduate. There are not other alternatives to the class. You find yourself struggling to get by in the class, even though you have 
attended all of the lectures and have completed all of the assignments on time. You meet with the instructor about the class, and she tells you that extra credit is not an option for the class. Based on the nature of the assignments, it is also impossible for you to cheat. You need to pass this class but are running out of options and don't think you will be able to bring your grade up enough by the end of the semester. Based on this information, answer the following questions. 


\section{APPENDIX B - Strain Questions}

Please take a moment and THINK ABOUT THE STRESSFUL SITUATION, and HOW IT MAKES YOU FEEL. Answer each of the following questions by choosing the number that corresponds to your judgment. Remember, there are no right or wrong answers.

1. Society is not fair to me.

Strongly Disagree

12

23

$3=4$

5

2. I wish I had more power in my life, but I cannot realize it according to some reason.

Strongly Disagree

12

3

4

5

6

$7 \quad 8$

8

Strongly Agree
9

3. I wish I could be successful, but there are too many obstacles in life.

\begin{tabular}{cccccccccc} 
Strongly & Disagree & & & & & & & \multicolumn{2}{c}{ Strongly Agree } \\
1 & 2 & 3 & 4 & 5 & 6 & 7 & 8 & 9 & 10
\end{tabular}

4. I believe I am good enough, but I am not satisfied with the treatment from others.

Strongly Disagree

12

34

5

6

7

8

Strongly Agree

9

10

5. I have worked too hard and gained too little.

\begin{tabular}{cccccccccc} 
Strongly & Disagree & & & & & & \multicolumn{2}{c}{ Strongly Agree } \\
1 & 2 & 3 & 4 & 5 & 6 & 7 & 8 & 9 & 10
\end{tabular}




\title{
APPENDIX C - Affective State
}

Please take a moment to THINK ABOUT THE STRESSFUL SITUATION you read at the beginning of the survey and HOW YOU MIGHT EMOTIONALLY REACT. Answer each of the following questions by choosing the number that corresponds to your judgment. Remember, there are no right or wrong answers.

\section{Anger/Frustration}

6. If I get upset, I might hit someone.

\begin{tabular}{cccccccccc} 
Strongly Disagree & & & & & & \multicolumn{2}{c}{ Strongly Agree } \\
1 & 2 & 3 & 4 & 5 & 6 & 7 & 8 & 9 & 10
\end{tabular}

7. If someone hit me, I hit him/her back.

Strongly Disagree

12

\section{3}

4

5

6

7

8. I get into physical fighting more often than others.

\begin{abstract}
Strongly Disagree
\end{abstract}

$1 \quad 2$

2

3

4

5

6

9. When I am upset, I feel like throwing things.

\section{Strongly Disagree \\ $1 \quad 2$}

34

5


Strongly Disagree

$1 \quad 2$

2

3

4

5

6

13. I sometimes feel very nervous with no particular reason.

$\begin{array}{cc}\text { Strongly } & \text { Disagree } \\ 1 & 2\end{array}$

$3 \quad 4 \quad 5$

$\begin{array}{lllll}6 & & & \text { Strongly Agree } \\ 6 & 7 & 8 & 9 & 10\end{array}$

14. I sometimes feel very lonely with no particular reason.

Strongly Disagree

$1 \quad 2$

3

$4 \quad 5$

6

15. I sometimes feel very sad with no particular reason.

Strongly Disagree

$1 \quad 2$

3

4

5

6

7

Strongly Agree
$9 \quad 10$ 


\section{APPENDIX D - Social Support}

Thinking about $\boldsymbol{A L} \boldsymbol{L}$ the people in your life, including FAMILY, FRIENDS, ROOMMATES, and ACQUAINTANCES, answer the following questions.

33. I have someone who I can really count on to distract me from my worries when I feel under stress.

\begin{tabular}{ccccccccccc} 
Strongly Disagree & & & & & & \multicolumn{3}{c}{ Strongly Agree } \\
1 & 2 & 3 & 4 & 5 & 6 & 7 & 8 & 9 & 10
\end{tabular}

34. I have someone who I can really count on to help me feel more relaxed when I am under pressure or tense.

\begin{tabular}{ccccccccccc} 
Strongly Disagree & & & & & & & \multicolumn{2}{c}{ Strongly Agree } \\
1 & 2 & 3 & 4 & 5 & 6 & 7 & 8 & 9 & 10
\end{tabular}

35. I have someone who accepts me completely, including both my best and worst points.

\begin{tabular}{ccccccccccc} 
Strongly Disagree & & & & & & & \multicolumn{2}{c}{ Strongly Agree } \\
1 & 2 & 3 & 4 & 5 & 6 & 7 & 8 & 9 & 10
\end{tabular}

36. I have someone who I can really count on to care about me, regardless of what is happening to me.

\begin{tabular}{ccccccccccc} 
Strongly Disagree & & & & & & & \multicolumn{2}{c}{ Strongly Agree } \\
1 & 2 & 3 & 4 & 5 & 6 & 7 & 8 & 9 & 10
\end{tabular}

37. I have someone who I can really count on to help me feel better when I am feeling generally down-in-thedumps.

\begin{tabular}{ccccccccccc} 
Strongly Disagree & & & & & & \multicolumn{2}{c}{ Strongly Agree } \\
1 & 2 & 3 & 4 & 5 & 6 & 7 & 8 & 9 & 10
\end{tabular}

38. I have someone who I can count on to console me when I am very upset.

Strongly Disagree

1.

2

34

5

6

8

Strongly Agree 


\section{APPENDIX E - Response to Strain}

Please rate the FREQUENCY with which you have ENGAGED IN THE FOLLOWING BEHAVIORS when experiencing ANY STRESSFUL SITUATION.

\section{Criminal Responses}

24. Internally damage or destroy property that does not belong to you.
Never

1

2

3

4

5

$6 \quad 7$
Very Often
10

25. Steal, take, or try to take something worth $\$ 1$ or less.
Never
1

2

3

4
5

6

26. Steal, take, or try to take something worth more than $\$ 100$.
Never
1

2

$3 \quad 4$

5

6

7

27. Physically hurt another person on purpose.

\begin{tabular}{|c|c|c|c|c|c|c|c|c|c|}
\hline Never & & & & & & & & & $y$ Often \\
\hline 1 & 2 & 3 & 4 & 5 & 6 & 7 & 8 & 9 & 10 \\
\hline
\end{tabular}

\section{Helping Behavior}

28. Assisted others in need.
Never

1

2

3

4

5
$\begin{array}{llllc}6 & 7 & 8 & 9 & 10\end{array}$

29. Donated to charity.
Never

1

2

5
$\begin{array}{llllc}6 & 7 & 8 & 9 & 10\end{array}$

34

30. Volunteered at a local organization.
Never
1

12

23

4

5
$\begin{array}{lllcc}6 & 7 & 8 & 9 & 10\end{array}$ 
31. Shared personal resources.

Never

1

2

3

4

5

6

$7 \quad 8$

8

9

Very Often

10

32. Cooperated with others to achieve a common goal.

$\begin{array}{rlllllllll}\text { Never } & 2 & 3 & 4 & 5 & 6 & 7 & 8 & 9 & \begin{array}{c}\text { Very Often } \\ 1\end{array} \\ & 2 & & & \end{array}$


APPENDIX F - Frequency of Strain Experience

Please indicate on the scale HOW OFTEN YOU EXPERIENCED each of the following IN THE PAST 12 MONTHS:

\section{Interpersonal}

16. Friend or acquaintance was rude to you.

Never

1

2

3

4

5

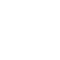

17. How did you react? Check all that apply. (If this did not happen to you, skip to question 19).

1. Hit something

2. Hit someone

3. Stole something valuable

4. Stole something of little worth

5. Used illegal drugs

6. Misused over the counter drugs

7. Volunteered your time

8. Donated to charity

9. Shared your belongings

10. Cooperated with others to achieve a common goal

11. Other

18. Friend or acquaintance spread rumors about you.

$\begin{array}{rlllllllll}\text { Never } & 2 & 3 & 4 & 5 & 6 & 7 & 8 & 9 & \begin{array}{c}\text { Very Often } \\ 1\end{array} \\ 1 & 2 & 3 & \end{array}$

19. How did you react? Check all that apply. (If this did not happen to you, skip to question 21).

1. Hit something

2. Hit someone

3. Stole something valuable

4. Stole something of little worth

5. Used illegal drugs

6. Misused over the counter drugs

7. Volunteered your time

8. Donated to charity

9. Shared your belongings

10. Cooperated with others to achieve a common goal

11. Other

20. Friend or acquaintance lied to you.

$\begin{array}{rlllllllll}\text { Never } & 2 & 3 & 4 & 5 & 6 & 7 & 8 & 9 & \begin{array}{c}\text { Very Often } \\ 1\end{array} \\ & 2 & 3 & 4 & 5 & \end{array}$

21. How did you react? Check all that apply. (If this did not happen to you, skip to question 23). 
1. Hit something

2. Hit someone

3. Stole something valuable

4. Stole something of little worth

5. Used illegal drugs

6. Misused over the counter drugs

7. Volunteered your time

8. Donated to charity

9. Shared your belongings

10. Cooperated with others to achieve a common goal

11. Other

22. Friend or acquaintance was insensitive to your problems.

Never

1

2

3

4

5

6

7

8

9

Very Often

10

23. How did you react? Check all that apply. (If this did not happen to you, skip this question).

1. Hit something

2. Hit someone

3. Stole something valuable

4. Stole something of little worth

5. Used illegal drugs

6. Misused over the counter drugs

7. Volunteered your time

8. Donated to charity

9. Shared your belongings

10. Cooperated with others to achieve a common goal

11. Other

Financial

16. Inability to pay bills.

Never

1

2

3

4

5

$\begin{array}{llll}6 & 7 & 8 & 9\end{array}$

Very Often

10

17. How did you react? Check all that apply. (If this did not happen to you, skip to question 19).

1. Hit something

2. Hit someone

3. Stole something valuable

4. Stole something of little worth

5. Used illegal drugs

6. Misused over the counter drugs

7. Volunteered your time

8. Donated to charity

9. Shared your belongings

10. Cooperated with others to achieve a common goal

11. Other 
18. Inability to buy food.

Never

2

2

3

4

5

6

7

$8+-9$

Very Often

19. How did you react? Check all that apply. (If this did not happen to you, skip to question 21).

1. Hit something

2. Hit someone

3. Stole something valuable

4. Stole something of little worth

5. Used illegal drugs

6. Misused over the counter drugs

7. Volunteered your time

8. Donated to charity

9. Shared your belongings

10. Cooperated with others to achieve a common goal

11. Other

20. Inability to buy clothing.

Never
1

2

3

4

5
$\begin{array}{llllc}6 & 7 & 8 & 9 & \text { Very Often } \\ 0 & 70\end{array}$

21. How did you react? Check all that apply. (If this did not happen to you, skip to question 23).

1. Hit something

2. Hit someone

3. Stole something valuable

4. Stole something of little worth

5. Used illegal drugs

6. Misused over the counter drugs

7. Volunteered your time

8. Donated to charity

9. Shared your belongings

10. Cooperated with others to achieve a common goal

11. Other

22. Inability to pay medical bills.

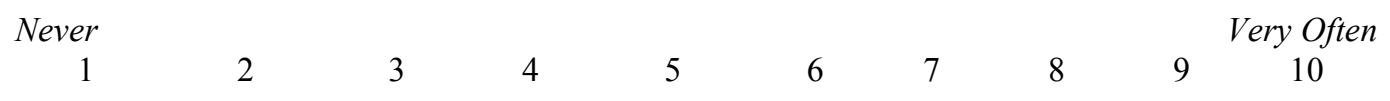

23. How did you react? Check all that apply. (If this did not happen to you, skip this question).

1. Hit something

2. Hit someone

3. Stole something valuable 
4. Stole something of little worth

5. Used illegal drugs

6. Misused over the counter drugs

7. Volunteered your time

8. Donated to charity

9. Shared your belongings

10. Cooperated with others to achieve a common goal

11. Other

\section{Victimization}

16. I have been bullied.

Never

1

2

3

4

5

6

7

8
Very Often
10

17. How did you react? Check all that apply. (If this did not happen to you, skip to question 19).

1. Hit something

2. Hit someone

3. Stole something valuable

4. Stole something of little worth

5. Used illegal drugs

6. Misused over the counter drugs

7. Volunteered your time

8. Donated to charity

9. Shared your belongings

10. Cooperated with others to achieve a common goal

11. Other

18. I have been hit.

\begin{tabular}{|c|c|c|c|c|c|c|c|c|c|}
\hline Never & & & & & & & & & Very Often \\
\hline 1 & 2 & 3 & 4 & 5 & 6 & 7 & 8 & 9 & 10 \\
\hline
\end{tabular}

19. How did you react? Check all that apply. (If this did not happen to you, skip to question 21).

1. Hit something

2. Hit someone

3. Stole something valuable

4. Stole something of little worth

5. Used illegal drugs

6. Misused over the counter drugs

7. Volunteered your time

8. Donated to charity

9. Shared your belongings

10. Cooperated with others to achieve a common goal

11. Other 
20. I have been yelled at.

Never

1

2

3

4

5

6

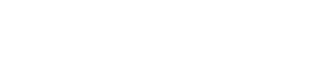

21. How did you react? Check all that apply. (If this did not happen to you, skip to question 23).
1. Hit something
2. Hit someone
3. Stole something valuable
4. Stole something of little worth
5. Used illegal drugs
6. Misused over the counter drugs
7. Volunteered your time
8. Donated to charity
9. Shared your belongings
10. Cooperated with others to achieve a common goal
11. Other

22. I have been robbed.
Never
1

2

3
4

5
$\begin{array}{llllc}6 & 7 & 8 & 9 & 10\end{array}$

23. How did you react? Check all that apply. (If this did not happen to you, skip this question).

1. Hit something

2. Hit someone

3. Stole something valuable

4. Stole something of little worth

5. Used illegal drugs

6. Misused over the counter drugs

7. Volunteered your time

8. Donated to charity

9. Shared your belongings

10. Cooperated with others to achieve a common goal

11. Other

\section{Academic}

16. I have gotten a bad grade.
Never
1
2
34

5
$6 \quad 7$
$8 \quad 9$
Very Often
10 
17. How did you react? Check all that apply. (If this did not happen to you, skip to question 19).

1. Hit something

2. Hit someone

3. Stole something valuable

4. Stole something of little worth

5. Used illegal drugs/Misused over the counter drugs

6. Volunteered your time

7. Donated to charity

8. Shared your belongings

9. Cooperated with others to achieve a common goal

10. Other

18. Homework has caused me stress.

Never

1

2

3

4

5

6

7

8

9

Very Often

10

19. How did you react? Check all that apply. (If this did not happen to you, skip to question 21).

1. Hit something

2. Hit someone

3. Stole something valuable

4. Stole something of little worth

5. Used illegal drugs/Misused over the counter drugs

6. Volunteered your time

7. Donated to charity

8. Shared your belongings

9. Cooperated with others to achieve a common goal

10. Other

20. I have failed a class.

Never

1

2

3

4

5

6

7

8

9

Very Often

10

21. How did you react? Check all that apply. (If this did not happen to you, skip to question 23).

1. Hit something

2. Hit someone

3. Stole something valuable

4. Stole something of little worth

5. Used illegal drugs/Misused over the counter drugs

6. Volunteered your time

7. Donated to charity

8. Shared your belongings

9. Cooperated with others to achieve a common goal

10. Other 
22. I have had to retake a class.

Never

1

2

3

4

5

6

7

89

Very Often

23. How did you react? Check all that apply. (If this did not happen to you, skip this question).

1. Hit something

2. Hit someone

3. Stole something valuable

4. Stole something of little worth

5. Used illegal drugs/Misused over the counter drugs

6. Volunteered your time

7. Donated to charity

8. Shared your belongings

9. Cooperated with others to achieve a common goal

10. Other 
PPENDIX G - Slider Bars

For the next part of the survey, you have been randomly paired with another person, whom we will refer to as the other. This other person is someone you do not know and will remain mutually anonymous. You will be making a series of decisions about allocating resources between you and this other person. For each of the following questions, please indicate the distribution you prefer most by marking the respective position by circling your choice. You can only make one mark for each question.

Your decisions will yield money for both yourself and the other person. In the example below, a person has chosen to distribute money so that he/she receives 93 dollars, while the anonymous other person receives 68 dollars.

There are no right or wrong answers, this is all about personal preferences. As you can see, your choices will influence both the amount of money you receive as well as the amount of money the other receives. All of your choices are completely confidential.

\section{EXAMPLE}
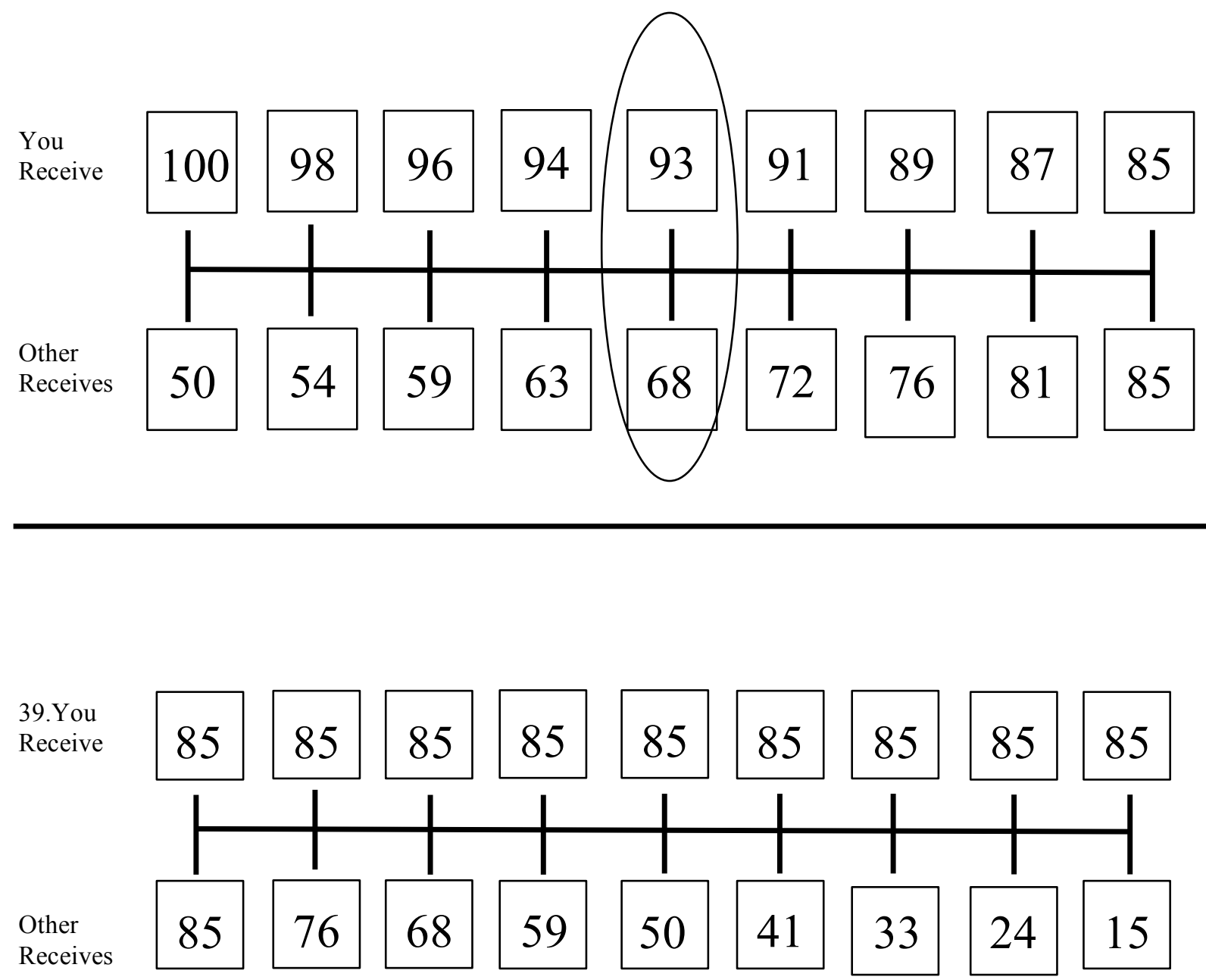

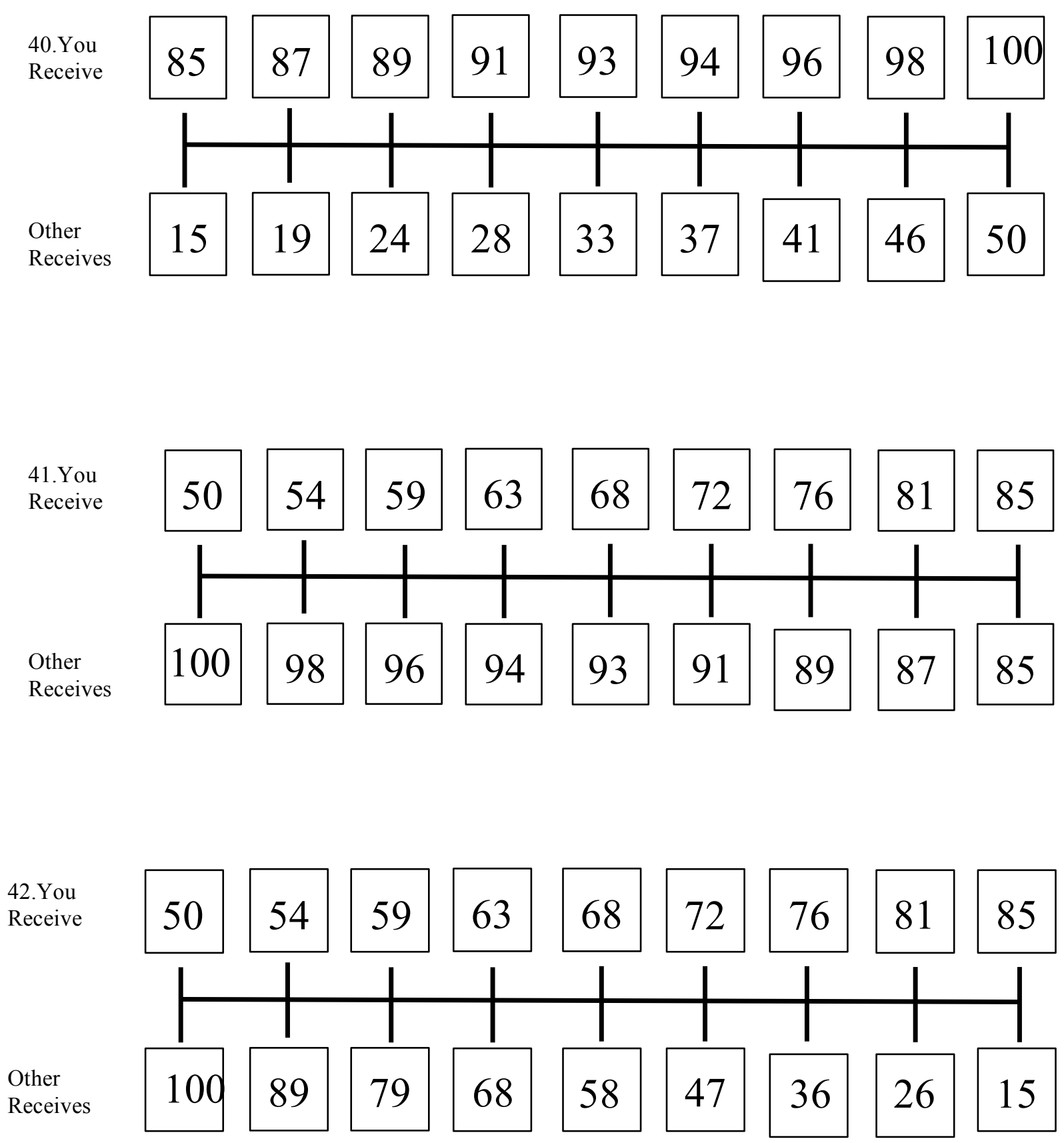

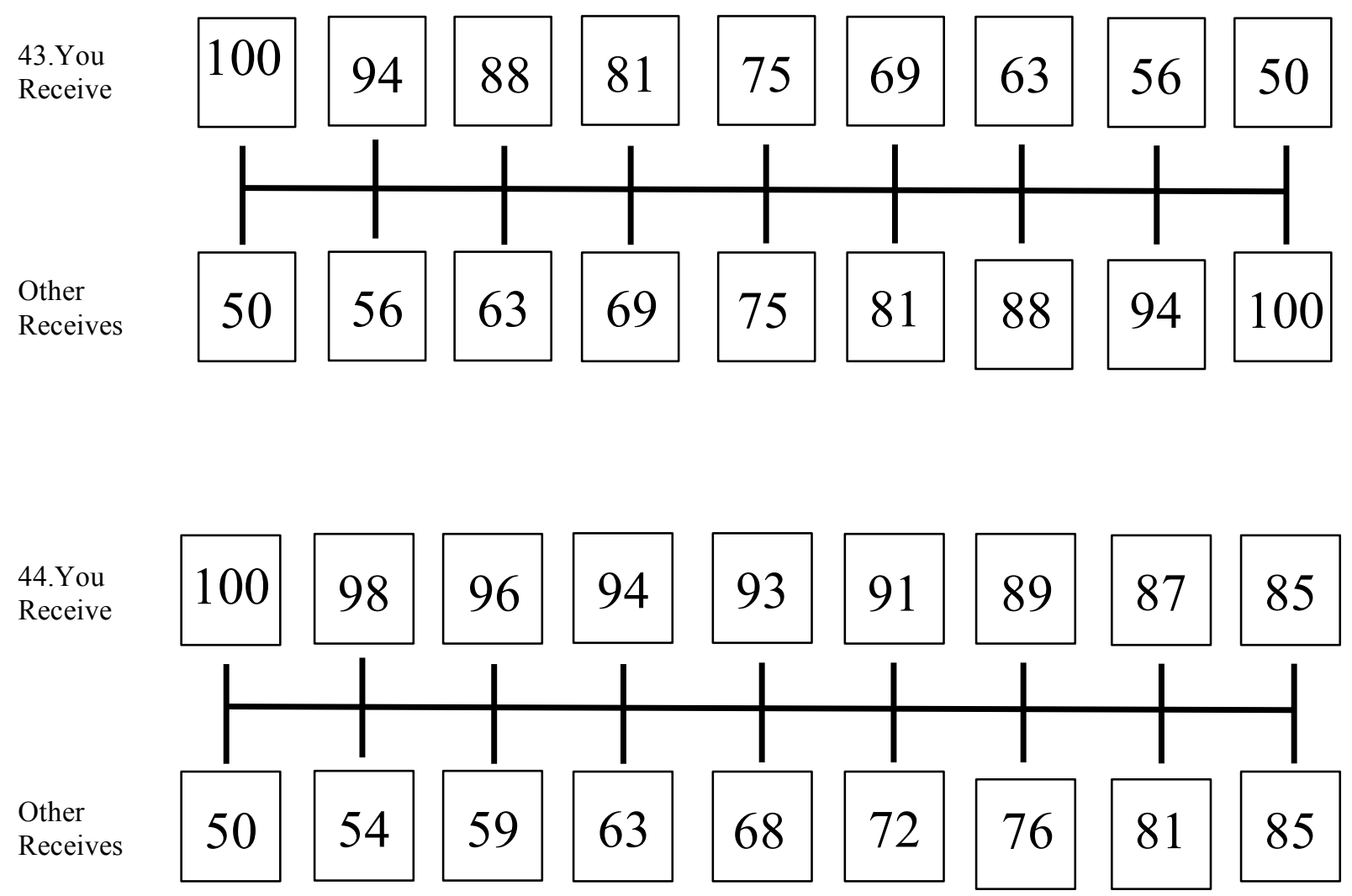
APPENDIX H - Tables of Direct, Indirect, and Total Effects for Moderating Path Analyses

Table H.1. Summary of Causal Effects for Academic Strain Moderator Path Analysis (Standardized Effects)

\begin{tabular}{|c|c|c|c|c|}
\hline \multirow[b]{2}{*}{ Dependent Variable } & \multirow[b]{2}{*}{ Independent Variable } & \multicolumn{3}{|c|}{ Causal Effects } \\
\hline & & Direct & Indirect & Total \\
\hline $\begin{array}{l}\text { Anger/Frustration } \\
\left(R^{2}=0.10\right)\end{array}$ & Academic Stressor & $0.32 * *$ & -- & $0.32 * *$ \\
\hline $\begin{array}{l}\text { Depression/Anxiety } \\
\left(R^{2}=0.21\right)\end{array}$ & Academic Stressor & $0.46 * * *$ & -- & $0.46 * * *$ \\
\hline \multirow[t]{4}{*}{$\begin{array}{l}\text { Crime/Deviance } \\
\left(R^{2}=0.09\right)\end{array}$} & Academic Stressor & -- & 0.06 & 0.06 \\
\hline & Anger/Frustration & 0.19 & -- & 0.19 \\
\hline & Social Support & -0.09 & -- & -0.09 \\
\hline & $\begin{array}{c}\text { Anger/Frustration* Social } \\
\text { Support }\end{array}$ & 0.24 & -- & 0.24 \\
\hline \multirow[t]{4}{*}{$\begin{array}{l}\text { Helping } \\
\left(R^{2}=0.21\right)\end{array}$} & Academic Stressor & -- & 0.16 & 0.16 \\
\hline & Depression/Anxiety & 0.34 & -- & 0.34 \\
\hline & Social Support & $0.38 * *$ & -- & $0.38 * *$ \\
\hline & $\begin{array}{c}\text { Depression/Anxiety*Social } \\
\text { Support }\end{array}$ & -0.18 & -- & -0.18 \\
\hline
\end{tabular}

Notes: $* p<0.05 ; * * p<0.01 ; * * * p<0.001$ (two-tailed tests) 
Table H.2. Summary of Causal Effects for Interpersonal Strain Moderator Path Analysis (Standardized Effects)

\begin{tabular}{|c|c|c|c|c|}
\hline \multirow[b]{2}{*}{ Dependent Variable } & \multirow[b]{2}{*}{ Independent Variable } & \multicolumn{3}{|c|}{ Causal Effects } \\
\hline & & Direct & Indirect & Total \\
\hline $\begin{array}{l}\text { Anger/Frustration } \\
\left(R^{2}=0.14\right)\end{array}$ & Interpersonal Stressor & $0.38 * * *$ & -- & $0.38 * * *$ \\
\hline $\begin{array}{l}\text { Depression/Anxiety } \\
\left(R^{2}=0.09\right)\end{array}$ & Interpersonal Stressor & $0.31 * *$ & -- & $0.31 * *$ \\
\hline \multirow[t]{4}{*}{$\begin{array}{l}\text { Crime/Deviance } \\
\left(R^{2}=0.35\right)\end{array}$} & Interpersonal Stressor & -- & 0.11 & 0.11 \\
\hline & Anger/Frustration & 0.30 & -- & 0.30 \\
\hline & Social Support & -0.25 & -- & -0.25 \\
\hline & $\begin{array}{c}\text { Anger/Frustration*Social } \\
\text { Support }\end{array}$ & 0.51 & -- & 0.51 \\
\hline \multirow[t]{4}{*}{$\begin{array}{l}\text { Helping } \\
\left(R^{2}=0.22\right)\end{array}$} & Interpersonal Stressor & -- & 0.11 & 0.11 \\
\hline & Depression/Anxiety & 0.35 & -- & 0.35 \\
\hline & Social Support & 0.33 & -- & 0.33 \\
\hline & $\begin{array}{c}\text { Depression/Anxiety*Social } \\
\text { Support }\end{array}$ & -0.11 & -- & -0.11 \\
\hline
\end{tabular}

Notes: ${ }^{*} p<0.05 ; * * p<0.01 ; * * * p<0.001$ (two-tailed tests) 
Table H.3. Summary of Causal Effects for Victimization Strain Moderator Path Analysis (Standardized Effects)

\begin{tabular}{|c|c|c|c|c|}
\hline \multirow[b]{2}{*}{ Dependent Variable } & \multirow[b]{2}{*}{ Independent Variable } & \multicolumn{3}{|c|}{ Causal Effects } \\
\hline & & Direct & Indirect & Total \\
\hline $\begin{array}{l}\text { Anger/Frustration } \\
\left(R^{2}=0.10\right)\end{array}$ & Victimization Stressor & $0.32 * *$ & -- & $0.32 * *$ \\
\hline $\begin{array}{l}\text { Depression/Anxiety } \\
\left(R^{2}=0.04\right)\end{array}$ & Victimization Stressor & 0.20 & -- & 0.20 \\
\hline \multirow[t]{4}{*}{$\begin{array}{l}\text { Crime/Deviance } \\
\left(R^{2}=0.39\right)\end{array}$} & Victimization Stressor & -- & 0.05 & 0.05 \\
\hline & Anger/Frustration & 0.14 & -- & 0.14 \\
\hline & Social Support & -0.21 & -- & -0.21 \\
\hline & $\begin{array}{c}\text { Anger/Frustration* Social } \\
\text { Support }\end{array}$ & $0.664 *$ & -- & $0.664^{*}$ \\
\hline \multirow[t]{4}{*}{$\begin{array}{l}\text { Helping } \\
\left(R^{2}=0.35\right)\end{array}$} & Victimization Stressor & -- & 0.07 & 0.07 \\
\hline & Depression/Anxiety & 0.35 & -- & 0.35 \\
\hline & Social Support & $0.57 *$ & -- & $0.57 *$ \\
\hline & $\begin{array}{c}\text { Depression/Anxiety*Social } \\
\text { Support }\end{array}$ & -0.30 & -- & -0.30 \\
\hline
\end{tabular}

Notes: ${ }^{*} p<0.05 ; * * p<0.01 ; * * * p<0.001$ (two-tailed tests) 
Table H.4. Summary of Causal Effects for Financial Strain Moderator Path Analysis (Standardized Effects)

\begin{tabular}{|c|c|c|c|c|}
\hline \multirow[b]{2}{*}{ Dependent Variable } & \multirow[b]{2}{*}{ Independent Variable } & \multicolumn{3}{|c|}{ Causal Effects } \\
\hline & & Direct & Indirect & Total \\
\hline $\begin{array}{l}\text { Anger/Frustration } \\
\left(R^{2}=0.14\right)\end{array}$ & Financial Stressor & $0.32 * *$ & -- & $0.32 * *$ \\
\hline $\begin{array}{l}\text { Depression/Anxiety } \\
\left(R^{2}=0.09\right)\end{array}$ & Financial Stressor & $0.35^{* *}$ & -- & $0.35 * *$ \\
\hline \multirow[t]{4}{*}{$\begin{array}{l}\text { Crime/Deviance } \\
\left(R^{2}=0.35\right)\end{array}$} & Financial Stressor & -- & 0.18 & 0.18 \\
\hline & Anger/Frustration & $0.57 *$ & -- & $0.57^{*}$ \\
\hline & Social Support & -0.05 & -- & -0.05 \\
\hline & $\begin{array}{c}\text { Anger/Frustration* Social } \\
\text { Support }\end{array}$ & 0.17 & -- & 0.17 \\
\hline \multirow[t]{4}{*}{$\begin{array}{l}\text { Helping } \\
\left(R^{2}=0.22\right)\end{array}$} & Financial Stressor & -- & -0.09 & -0.09 \\
\hline & Depression/Anxiety & -0.27 & -- & -0.27 \\
\hline & Social Support & $0.36^{*}$ & -- & $0.36^{*}$ \\
\hline & $\begin{array}{c}\text { Depression/Anxiety*Social } \\
\text { Support }\end{array}$ & 0.40 & -- & 0.40 \\
\hline
\end{tabular}

Notes: ${ }^{*} p<0.05 ; * * p<0.01 ; * * * p<0.001$ (two-tailed tests) 
Table H.5. Summary of Causal Effects for Academic Strain Moderator for Males Path Analysis (Standardized Effects)

\begin{tabular}{|c|c|c|c|c|}
\hline \multirow[b]{2}{*}{ Dependent Variable } & \multirow[b]{2}{*}{ Independent Variable } & \multicolumn{3}{|c|}{ Causal Effects } \\
\hline & & Direct & Indirect & Total \\
\hline $\begin{array}{l}\text { Anger/Frustration } \\
\left(R^{2}=0.000\right)\end{array}$ & Academic Stressor & -0.01 & -- & -0.01 \\
\hline $\begin{array}{l}\text { Depression/Anxiety } \\
\left(R^{2}=0.24\right)\end{array}$ & Academic Stressor & $0.47 * *$ & -- & $0.49 * *$ \\
\hline \multirow[t]{4}{*}{$\begin{array}{l}\text { Crime/Deviance } \\
\left(R^{2}=0.34\right)\end{array}$} & Academic Stressor & -- & 0.001 & 0.001 \\
\hline & Anger/Frustration & -0.11 & -- & -0.11 \\
\hline & Social Support & -0.46 & -- & -0.46 \\
\hline & $\begin{array}{c}\text { Anger/Frustration* Social } \\
\text { Support }\end{array}$ & $0.78 *$ & -- & $0.78^{*}$ \\
\hline \multirow[t]{4}{*}{$\begin{array}{l}\text { Helping } \\
\left(R^{2}=0.44\right)\end{array}$} & Academic Stressor & -- & -0.06 & -0.06 \\
\hline & Depression/Anxiety & -0.12 & -- & -0.12 \\
\hline & Social Support & 0.18 & -- & 0.18 \\
\hline & $\begin{array}{c}\text { Depression/Anxiety*Social } \\
\text { Support }\end{array}$ & 0.55 & -- & 0.55 \\
\hline
\end{tabular}

Notes: ${ }^{*} p<0.05 ; * * p<0.01 ; * * * p<0.001$ (two-tailed tests) 
Table H.6. Summary of Causal Effects for Academic Strain Moderator for Males Path Analysis (Standardized Effects)

\begin{tabular}{|c|c|c|c|c|}
\hline \multirow[b]{2}{*}{ Dependent Variable } & \multirow[b]{2}{*}{ Independent Variable } & \multicolumn{3}{|c|}{ Causal Effects } \\
\hline & & Direct & Indirect & Total \\
\hline $\begin{array}{l}\text { Anger/Frustration } \\
\left(R^{2}=0.21\right)\end{array}$ & Academic Stressor & $0.46^{* * *}$ & -- & $0.46 * * *$ \\
\hline $\begin{array}{l}\text { Depression/Anxiety } \\
\left(R^{2}=0.13\right)\end{array}$ & Academic Stressor & $0.36^{* *}$ & -- & $0.36^{* *}$ \\
\hline \multirow[t]{4}{*}{$\begin{array}{l}\text { Crime/Deviance } \\
\left(R^{2}=0.51\right)\end{array}$} & Academic Stressor & -- & 0.30 & 0.30 \\
\hline & Anger/Frustration & 0.66 & -- & 0.66 \\
\hline & Social Support & 0.09 & -- & 0.09 \\
\hline & $\begin{array}{l}\text { Anger/Frustration*Social } \\
\text { Support }\end{array}$ & -0.46 & -- & -0.46 \\
\hline \multirow[t]{4}{*}{$\begin{array}{l}\text { Helping } \\
\left(R^{2}=0.10\right)\end{array}$} & Academic Stressor & -- & 0.09 & 0.09 \\
\hline & Depression/Anxiety & 0.24 & -- & 0.24 \\
\hline & Social Support & 0.22 & -- & 0.22 \\
\hline & $\begin{array}{c}\text { Depression/Anxiety*Social } \\
\text { Support }\end{array}$ & -0.21 & -- & -0.21 \\
\hline
\end{tabular}

Notes: ${ }^{*} p<0.05 ; * * p<0.01 ; * * * p<0.001$ (two-tailed tests) 
APPENDIX I - Tables of Direct, Indirect, and Total Effects for Mediating Path Analyses Table I.1. Summary of Causal Effects for Academic Strain Path Analysis (Standardized Effects)

\begin{tabular}{|c|c|c|c|c|}
\hline \multirow[b]{2}{*}{ Dependent Variable } & \multirow[b]{2}{*}{ Independent Variable } & \multicolumn{3}{|c|}{ Causal Effects } \\
\hline & & Direct & Indirect & Total \\
\hline $\begin{array}{l}\text { Anger/Frustration } \\
\left(R^{2}=0.10\right)\end{array}$ & Academic Stressor & $0.32 * *$ & -- & $0.32 * *$ \\
\hline $\begin{array}{l}\text { Depression/Anxiety } \\
\left(R^{2}=0.21\right)\end{array}$ & Academic Stressor & $0.46^{* * *}$ & -- & $0.46^{* * *}$ \\
\hline \multirow[t]{3}{*}{$\begin{array}{l}\text { Social Support } \\
\left(R^{2}=0.01\right)\end{array}$} & Anger/Frustration & 0.09 & -- & 0.09 \\
\hline & Depression/Anxiety & -0.01 & -- & -0.01 \\
\hline & Academic Stressor & -- & 0.03 & 0.03 \\
\hline \multirow[t]{4}{*}{$\begin{array}{l}\text { Crime/Deviance } \\
\left(R^{2}=0.14\right)\end{array}$} & Academic Stressor & -- & $0.12^{*}$ & $0.12 *$ \\
\hline & Anger/Frustration & $0.37 * *$ & 0.00 & $0.38 * *$ \\
\hline & Social Support & 0.01 & -- & 0.01 \\
\hline & Depression/Anxiety & -- & -0.00 & $0.12 *$ \\
\hline \multirow[t]{4}{*}{$\begin{array}{l}\text { Helping } \\
\left(R^{2}=0.13\right)\end{array}$} & Academic Stressor & -- & $0.10^{*}$ & $0.10^{*}$ \\
\hline & Depression/Anxiety & $0.20 *$ & -0.00 & $0.20^{*}$ \\
\hline & Social Support & $0.30 * *$ & -- & $0.30 * *$ \\
\hline & Anger/Frustration & -- & 0.03 & 0.03 \\
\hline
\end{tabular}

Notes: ${ }^{*} p<0.05 ;{ }^{* *} p<0.01 ;{ }^{* * *} p<0.001$ (two-tailed tests) 
Table I.2. Summary of Causal Effects for Interpersonal Strain Path Analysis (Standardized Effects)

\begin{tabular}{|c|c|c|c|c|}
\hline \multirow[b]{2}{*}{ Dependent Variable } & \multirow[b]{2}{*}{ Independent Variable } & \multicolumn{3}{|c|}{ Causal Effects } \\
\hline & & Direct & Indirect & Total \\
\hline $\begin{array}{l}\text { Anger/Frustration } \\
\left(R^{2}=0.14\right)\end{array}$ & Interpersonal Stressor & $0.38 * * *$ & -- & $0.38 * * *$ \\
\hline $\begin{array}{l}\text { Depression/Anxiety } \\
\left(R^{2}=0.09\right)\end{array}$ & Interpersonal Stressor & $0.31 * *$ & -- & $0.31 * *$ \\
\hline \multirow[t]{3}{*}{$\begin{array}{l}\text { Social Support } \\
\left(R^{2}=0.01\right)\end{array}$} & Anger/Frustration & -0.01 & -- & -0.01 \\
\hline & Depression/Anxiety & -0.11 & -- & -0.11 \\
\hline & Interpersonal Stressor & -- & -0.04 & -0.04 \\
\hline \multirow[t]{4}{*}{$\begin{array}{l}\text { Crime/Deviance } \\
\left(R^{2}=0.45\right)\end{array}$} & Interpersonal Stressor & -- & $0.26 * * *$ & $0.26 * * *$ \\
\hline & Anger/Frustration & $0.67 * * *$ & 0.00 & $0.67 * * *$ \\
\hline & Social Support & -0.02 & -- & -0.02 \\
\hline & Depression/Anxiety & -- & 0.00 & 0.00 \\
\hline \multirow[t]{4}{*}{$\begin{array}{l}\text { Helping } \\
\left(R^{2}=0.25\right)\end{array}$} & Interpersonal Stressor & -- & $0.16^{*}$ & $0.16^{*}$ \\
\hline & Depression/Anxiety & 0.06 & -0.03 & 0.03 \\
\hline & Social Support & $0.29 * *$ & -- & $0.29 * *$ \\
\hline & Anger/Frustration & $0.39 * * *$ & -0.00 & $0.39 * * *$ \\
\hline
\end{tabular}

Notes: ${ }^{*} p<0.05 ; * * p<0.01 ; * * * p<0.001$ (two-tailed tests) 
Table I.3. Summary of Causal Effects for Victimization Strain Path Analysis (Standardized Effects)

\begin{tabular}{|c|c|c|c|c|}
\hline \multirow[b]{2}{*}{ Dependent Variable } & \multirow[b]{2}{*}{ Independent Variable } & \multicolumn{3}{|c|}{ Causal Effects } \\
\hline & & Direct & Indirect & Total \\
\hline $\begin{array}{l}\text { Anger/Frustration } \\
\left(R^{2}=0.10\right)\end{array}$ & Victimization Stressor & $0.32 * *$ & -- & $0.32 * * *$ \\
\hline $\begin{array}{l}\text { Depression/Anxiety } \\
\left(R^{2}=0.04\right)\end{array}$ & Victimization Stressor & 0.20 & -- & 0.20 \\
\hline \multirow[t]{3}{*}{$\begin{array}{l}\text { Social Support } \\
\left(R^{2}=0.02\right)\end{array}$} & Anger/Frustration & -0.12 & -- & -0.12 \\
\hline & Depression/Anxiety & 0.16 & -- & 0.16 \\
\hline & Victimization Stressor & -- & -0.01 & -0.01 \\
\hline \multirow[t]{4}{*}{$\begin{array}{l}\text { Crime/Deviance } \\
\left(R^{2}=0.44\right)\end{array}$} & Victimization Stressor & -- & $0.21 * *$ & $0.21 * *$ \\
\hline & Anger/Frustration & $0.66^{* * *}$ & -0.01 & $0.65 * * *$ \\
\hline & Social Support & 0.10 & -- & 0.10 \\
\hline & Depression/Anxiety & -- & 0.02 & 0.02 \\
\hline \multirow[t]{4}{*}{$\begin{array}{l}\text { Helping } \\
\left(R^{2}=0.24\right)\end{array}$} & Victimization Stressor & -- & 0.02 & 0.02 \\
\hline & Depression/Anxiety & 0.11 & 0.08 & 0.19 \\
\hline & Social Support & $0.47 * * *$ & -- & $0.47 * * *$ \\
\hline & Anger/Frustration & -- & -0.06 & -0.06 \\
\hline
\end{tabular}

Notes: $* p<0.05 ; * * p<0.01 ; * * * p<0.001$ (two-tailed tests) 
Table I.4. Summary of Causal Effects for Financial Strain Path Analysis (Standardized Effects)

\begin{tabular}{|c|c|c|c|c|}
\hline \multirow[b]{2}{*}{ Dependent Variable } & \multirow[b]{2}{*}{ Independent Variable } & \multicolumn{3}{|c|}{ Causal Effects } \\
\hline & & Direct & Indirect & Total \\
\hline $\begin{array}{l}\text { Anger/Frustration } \\
\left(R^{2}=0.10\right)\end{array}$ & Financial Stressor & $0.32 * *$ & -- & $0.32 * *$ \\
\hline $\begin{array}{l}\text { Depression/Anxiety } \\
\left(R^{2}=0.12\right)\end{array}$ & Financial Stressor & $0.35 * *$ & -- & $0.35 * *$ \\
\hline \multirow[t]{3}{*}{$\begin{array}{l}\text { Social Support } \\
\left(R^{2}=0.01\right)\end{array}$} & Anger/Frustration & 0.05 & -- & 0.05 \\
\hline & Depression/Anxiety & 0.07 & -- & 0.07 \\
\hline & Financial Stressor & -- & 0.04 & 0.04 \\
\hline \multirow[t]{4}{*}{$\begin{array}{l}\text { Crime/Deviance } \\
\left(R^{2}=0.44\right)\end{array}$} & Financial Stressor & -- & $0.21 * *$ & $0.21 * *$ \\
\hline & Anger/Frustration & $0.66^{* * *}$ & 0.00 & $0.66^{* * *}$ \\
\hline & Social Support & 0.02 & -- & 0.02 \\
\hline & Depression/Anxiety & -- & 0.00 & 0.00 \\
\hline \multirow[t]{4}{*}{$\begin{array}{l}\text { Helping } \\
\left(R^{2}=0.43\right)\end{array}$} & Financial Stressor & -- & 0.07 & 0.07 \\
\hline & Depression/Anxiety & -0.15 & 0.04 & -0.11 \\
\hline & Social Support & $0.60 * * *$ & -- & $0.60 * * *$ \\
\hline & Anger/Frustration & $0.30 * *$ & 0.03 & $0.33 * *$ \\
\hline
\end{tabular}

Notes: $* p<0.05 ; * * p<0.01 ; * * * p<0.001$ (two-tailed tests) 
Table I.5. Summary of Causal Effects for Academic Strain Path Analysis for Males (Standardized Effects)

\begin{tabular}{|c|c|c|c|c|}
\hline \multirow[b]{2}{*}{ Dependent Variable } & \multirow[b]{2}{*}{ Independent Variable } & \multicolumn{3}{|c|}{ Causal Effects } \\
\hline & & Direct & Indirect & Total \\
\hline $\begin{array}{l}\text { Anger/Frustration } \\
\left(R^{2}=0.00\right)\end{array}$ & Academic Stressor & -0.01 & -- & -0.01 \\
\hline $\begin{array}{l}\text { Depression/Anxiety } \\
\left(R^{2}=0.24\right)\end{array}$ & Academic Stressor & $0.49 * *$ & -- & $0.49 * *$ \\
\hline \multirow[t]{3}{*}{$\begin{array}{l}\text { Social Support } \\
\left(R^{2}=0.03\right)\end{array}$} & Anger/Frustration & -0.04 & -- & -0.04 \\
\hline & Depression/Anxiety & 0.19 & -- & 0.19 \\
\hline & Academic Stressor & -- & 0.09 & 0.09 \\
\hline \multirow[t]{4}{*}{$\begin{array}{l}\text { Crime/Deviance } \\
\left(R^{2}=0.19\right)\end{array}$} & Academic Stressor & -- & 0.00 & 0.00 \\
\hline & Anger/Frustration & 0.43 & -0.00 & 0.42 \\
\hline & Social Support & 0.09 & -- & 0.09 \\
\hline & Depression/Anxiety & -- & 0.02 & 0.02 \\
\hline \multirow[t]{4}{*}{$\begin{array}{l}\text { Helping } \\
\left(R^{2}=0.36\right)\end{array}$} & Academic Stressor & -- & 0.19 & 0.19 \\
\hline & Depression/Anxiety & $0.30 *$ & 0.09 & $0.39^{*}$ \\
\hline & Social Support & $0.46^{* *}$ & -- & $0.46^{* *}$ \\
\hline & Anger/Frustration & -- & -0.02 & -0.02 \\
\hline
\end{tabular}

Notes: $* p<0.05 ; * * p<0.01 ; * * * p<0.001$ (two-tailed tests) 
Table I.6. Summary of Causal Effects for Academic Strain Path Analysis for Males (Standardized Effects)

\begin{tabular}{|c|c|c|c|c|}
\hline \multirow[b]{2}{*}{ Dependent Variable } & \multirow[b]{2}{*}{ Independent Variable } & \multicolumn{3}{|c|}{ Causal Effects } \\
\hline & & Direct & Indirect & Total \\
\hline $\begin{array}{l}\text { Anger/Frustration } \\
\left(R^{2}=0.21\right)\end{array}$ & Academic Stressor & $0.46 * * *$ & -- & $0.46 * * *$ \\
\hline $\begin{array}{l}\text { Depression/Anxiety } \\
\left(R^{2}=0.13\right)\end{array}$ & Academic Stressor & $0.36^{* *}$ & -- & $0.36 * *$ \\
\hline \multirow[t]{3}{*}{$\begin{array}{l}\text { Social Support } \\
\left(R^{2}=0.09\right)\end{array}$} & Anger/Frustration & 0.20 & -- & 0.20 \\
\hline & Depression/Anxiety & -0.26 & -- & -0.26 \\
\hline & Academic Stressor & -- & -0.01 & -0.01 \\
\hline \multirow[t]{4}{*}{$\begin{array}{l}\text { Crime/Deviance } \\
\left(R^{2}=0.11\right)\end{array}$} & Academic Stressor & -- & 0.15 & 0.15 \\
\hline & Anger/Frustration & $0.33 *$ & -0.01 & $0.32 *$ \\
\hline & Social Support & -0.04 & -- & -0.04 \\
\hline & Depression/Anxiety & -- & 0.01 & 0.01 \\
\hline \multirow[t]{4}{*}{$\begin{array}{l}\text { Helping } \\
\left(R^{2}=0.01\right)\end{array}$} & Academic Stressor & -- & 0.02 & 0.02 \\
\hline & Depression/Anxiety & 0.05 & -0.03 & 0.03 \\
\hline & Social Support & 0.10 & -- & 0.10 \\
\hline & Anger/Frustration & -- & 0.02 & 0.02 \\
\hline
\end{tabular}

Notes: $* p<0.05 ; * * p<0.01 ; * * * p<0.001$ (two-tailed tests) 